\title{
A Review on Nanofluids: Preparation, Stability Mechanisms, and Applications
}

\author{
Wei Yu and Huaqing Xie \\ School of Urban Development and Environmental Engineering, Shanghai Second Polytechnic University, Shanghai 201209, China \\ Correspondence should be addressed to Huaqing Xie, hqxie@eed.sspu.cn \\ Received 21 April 2011; Accepted 11 July 2011 \\ Academic Editor: Li-Hong Liu \\ Copyright () 2012 W. Yu and H. Xie. This is an open access article distributed under the Creative Commons Attribution License, \\ which permits unrestricted use, distribution, and reproduction in any medium, provided the original work is properly cited.
}

Nanofluids, the fluid suspensions of nanomaterials, have shown many interesting properties, and the distinctive features offer unprecedented potential for many applications. This paper summarizes the recent progress on the study of nanofluids, such as the preparation methods, the evaluation methods for the stability of nanofluids, and the ways to enhance the stability for nanofluids, the stability mechanisms of nanofluids, and presents the broad range of current and future applications in various fields including energy and mechanical and biomedical fields. At last, the paper identifies the opportunities for future research.

\section{Introduction}

Nanofluids are a new class of fluids engineered by dispersing nanometer-sized materials (nanoparticles, nanofibers, nanotubes, nanowires, nanorods, nanosheet, or droplets) in base fluids. In other words, nanofluids are nanoscale colloidal suspensions containing condensed nanomaterials. They are two-phase systems with one phase (solid phase) in another (liquid phase). Nanofluids have been found to possess enhanced thermophysical properties such as thermal conductivity, thermal diffusivity, viscosity, and convective heat transfer coefficients compared to those of base fluids like oil or water. It has demonstrated great potential applications in many fields.

For a two-phase system, there are some important issues we have to face. One of the most important issues is the stability of nanofluids, and it remains a big challenge to achieve desired stability of nanofluids. In this paper, we will review the new progress in the methods for preparing stable nanofluids and summarize the stability mechanisms.

In recent years, nanofluids have attracted more and more attention. The main driving force for nanofluids research lies in a wide range of applications. Although some review articles involving the progress of nanofluid investigation were published in the past several years [1-6], most of the reviews are concerned of the experimental and theoretical studies of the thermophysical properties or the convective heat transfer of nanofluids. The purpose of this paper will focuses on the new preparation methods and stability mechanisms, especially the new application trends for nanofluids in addition to the heat transfer properties of nanofluids. We will try to find some challenging issues that need to be solved for future research based on the review on these aspects of nanofluids.

\section{Preparation Methods for Nanofluids}

2.1. Two-Step Method. Two-step method is the most widely used method for preparing nanofluids. Nanoparticles, nanofibers, nanotubes, or other nanomaterials used in this method are first produced as dry powders by chemical or physical methods. Then, the nanosized powder will be dispersed into a fluid in the second processing step with the help of intensive magnetic force agitation, ultrasonic agitation, high-shear mixing, homogenizing, and ball milling. Two-step method is the most economic method to produce nanofluids in large scale, because nanopowder synthesis techniques have already been scaled up to industrial production levels. Due to the high surface area and surface activity, nanoparticles have the tendency to aggregate. The important technique to enhance the stability of nanoparticles in fluids is the use of surfactants. However, the functionality of the surfactants under high temperature is also a big concern, especially for high-temperature applications. 
Due to the difficulty in preparing stable nanofluids by two-step method, several advanced techniques are developed to produce nanofluids, including one-step method. In the following part, we will introduce one-step method in detail.

2.2. One-Step Method. To reduce the agglomeration of nanoparticles, Eastman et al. developed a one-step physical vapor condensation method to prepare $\mathrm{Cu}$ /ethylene glycol nanofluids [7]. The one-step process consists of simultaneously making and dispersing the particles in the fluid. In this method, the processes of drying, storage, transportation, and dispersion of nanoparticles are avoided, so the agglomeration of nanoparticles is minimized, and the stability of fluids is increased [5]. The one-step processes can prepare uniformly dispersed nanoparticles, and the particles can be stably suspended in the base fluid. The vacuum-SANSS (submerged arc nanoparticle synthesis system) is another efficient method to prepare nanofluids using different dielectric liquids $[8,9]$. The different morphologies are mainly influenced and determined by various thermal conductivity properties of the dielectric liquids. The nanoparticles prepared exhibit needle-like, polygonal, square, and circular morphological shapes. The method avoids the undesired particle aggregation fairly well.

One-step physical method cannot synthesize nanofluids in large scale, and the cost is also high, so the one-step chemical method is developing rapidly. Zhu et al. presented a novel one-step chemical method for preparing copper nanofluids by reducing $\mathrm{CuSO}_{4} \cdot 5 \mathrm{H}_{2} \mathrm{O}$ with $\mathrm{NaH}_{2} \mathrm{PO}_{2}$. $\mathrm{H}_{2} \mathrm{O}$ in ethylene glycol under microwave irradiation [10]. Well-dispersed and stably suspended copper nanofluids were obtained. Mineral oil-based nanofluids containing silver nanoparticles with a narrow-size distribution were also prepared by this method [11]. The particles could be stabilized by Korantin, which coordinated to the silver particle surfaces via two oxygen atoms forming a dense layer around the particles. The silver nanoparticle suspensions were stable for about 1 month. Stable ethanol-based nanofluids containing silver nanoparticles could be prepared by microwave-assisted one-step method [12]. In the method, polyvinylpyrrolidone (PVP) was employed as the stabilizer of colloidal silver and reducing agent for silver in solution. The cationic surfactant octadecylamine (ODA) is also an efficient phase-transfer agent to synthesize silver colloids [13]. The phase transfer of the silver nanoparticles arises due to coupling of the silver nanoparticles with the ODA molecules present in organic phase via either coordination bond formation or weak covalent interaction. Phase transfer method has been developed for preparing homogeneous and stable graphene oxide colloids. Graphene oxide nanosheets (GONs) were successfully transferred from water to n-octane after modification by oleylamine, and the schematic illustration of the phase transfer process is shown in Figure 1 [14].

However, there are some disadvantages for one-step method. The most important one is that the residual reactants are left in the nanofluids due to incomplete reaction or stabilization. It is difficult to elucidate the nanoparticle effect without eliminating this impurity effect.

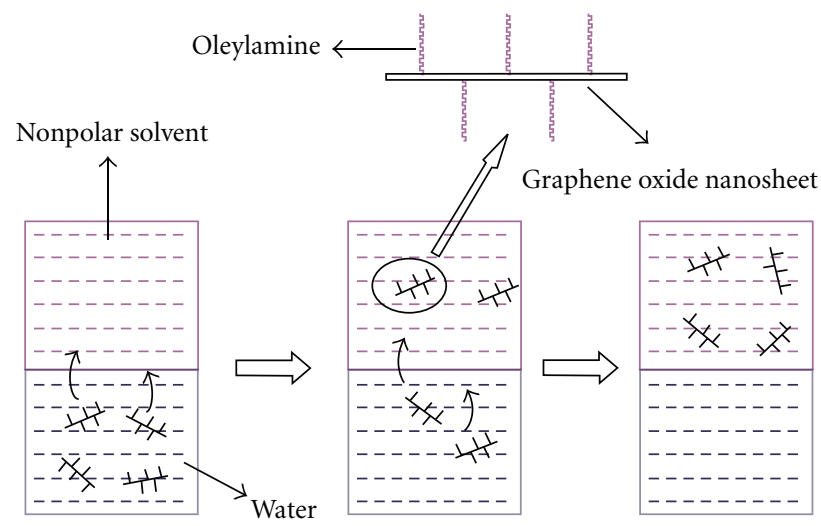

FIgURE 1: Schematic illustration of the phase transfer process.

2.3. Other Novel Methods. Wei et al. developed a continuousflow microfluidic microreactor to synthesize copper nanofluids. By this method, copper nanofluids can be continuously synthesized, and their microstructure and properties can be varied by adjusting parameters such as reactant concentration, flow rate, and additive. $\mathrm{CuO}$ nanofluids with high solid volume fraction (up to $10 \mathrm{vol} \%$ ) can be synthesized through a novel precursor transformation method with the help of ultrasonic and microwave irradiation [15]. The precursor $\mathrm{Cu}(\mathrm{OH})_{2}$ is completely transformed to $\mathrm{CuO}$ nanoparticle in water under microwave irradiation. The ammonium citrate prevents the growth and aggregation of nanoparticles, resulting in a stable $\mathrm{CuO}$ aqueous nanofluid with higher thermal conductivity than those prepared by other dispersing methods. Phase-transfer method is also a facile way to obtain monodisperse noble metal colloids [16]. In a watercyclohexane two-phase system, aqueous formaldehyde is transferred to cyclohexane phase via reaction with dodecylamine to form reductive intermediates in cyclohexane. The intermediates are capable of reducing silver or gold ions in aqueous solution to form dodecylamine-protected silver and gold nanoparticles in cyclohexane solution at room temperature. Feng et al. used the aqueous organic phasetransfer method for preparing gold, silver, and platinum nanoparticles on the basis of the decrease of the PVP's solubility in water with the temperature increase [17]. Phasetransfer method is also applied for preparing stable kerosenebased $\mathrm{Fe}_{3} \mathrm{O}_{4}$ nanofluids. Oleic acid is successfully grafted onto the surface of $\mathrm{Fe}_{3} \mathrm{O}_{4}$ nanoparticles by chemisorbed mode, which lets $\mathrm{Fe}_{3} \mathrm{O}_{4}$ nanoparticles have good compatibility with kerosene [18]. The $\mathrm{Fe}_{3} \mathrm{O}_{4}$ nanofluids prepared by phase-transfer method do not show the previously reported "time dependence of the thermal conductivity characteristic". The preparation of nanofluids with controllable microstructure is one of the key issues. It is well known that the properties of nanofluids strongly depend on the structure and shape of nanomaterials. The recent research shows that nanofluids synthesized by chemical solution method have both higher conductivity enhancement and better stability than those produced by the other methods [19]. This method is distinguished from the others by its controllability. The nanofluid microstructure can be varied 
and manipulated by adjusting synthesis parameters such as temperature, acidity, ultrasonic and microwave irradiation, types and concentrations of reactants and additives, and the order in which the additives are added to the solution.

\section{The Stability of Nanofluid}

The agglomeration of nanoparticles results in not only the settlement and clogging of microchannels but also the decreasing of thermal conductivity of nanofluids. So, the investigation on stability is also a key issue that influences the properties of nanofluids for application, and it is necessary to study and analyze influencing factors to the dispersion stability of nanofluids. This section will contain (a) the stability evaluation methods for nanofluids, (b) the ways to enhance the stability of nanofluids, and (c) the stability mechanisms of nanofluids.

\subsection{The Stability Evaluation Methods for Nanofluids}

3.1.1. Sedimentation and Centrifugation Methods. Many methods have been developed to evaluate the stability of nanofluids. The simplest method is sedimentation method $[20,21]$. The sediment weight or the sediment volume of nanoparticles in a nanofluid under an external force field is an indication of the stability of the characterized nanofluid. The variation of concentration or particle size of supernatant particle with sediment time can be obtained by special apparatus [5]. The nanofluids are considered to be stable when the concentration or particle size of supernatant particles keeps constant. Sedimentation photograph of nanofluids in test tubes taken by a camera is also a usual method for observing the stability of nanofluids [5]. Zhu et al. used a sedimentation balance method to measure the stability of the graphite suspension [22]. The tray of sedimentation balance immerged in the fresh graphite suspension. The weight of sediment nanoparticles during a certain period was measured. The suspension fraction of graphite nanoparticles at a certain time could be calculated. For the sedimentation method, long period for observation is the defect. Therefore, centrifugation method is developed to evaluate the stability of nanofluids. Singh et al. applied the centrifugation method to observe the stability of silver nanofluids prepared by the microwave synthesis in ethanol by reduction of $\mathrm{Ag} \mathrm{NO}_{3}$ with PVP as stabilizing agent [12]. It has been found that the obtained nanofluids are stable for more than 1 month in the stationary state and more than $10 \mathrm{~h}$ under centrifugation at 3,000 rpm without sedimentation. Excellent stability of the obtained nanofluid is due to the protective role of PVP, as it retards the growth and agglomeration of nanoparticles by steric effect. Li prepared the aqueous polyaniline colloids and used the centrifugation method to evaluate the stability of the colloids [23]. Electrostatic repulsive forces between nanofibers enabled the long-term stability of the colloids.

3.1.2. Zeta Potential Analysis. Zeta potential is electric potential in the interfacial double layer at the location of the slipping plane versus a point in the bulk fluid away from the interface, and it shows the potential difference between the dispersion medium and the stationary layer of fluid attached to the dispersed particle. The significance of zeta potential is that its value can be related to the stability of colloidal dispersions. So, colloids with high zeta potential (negative or positive) are electrically stabilized, while colloids with low zeta potentials tend to coagulate or flocculate. In general, a value of $25 \mathrm{mV}$ (positive or negative) can be taken as the arbitrary value that separates low-charged surfaces from highly charged surfaces. The colloids with zeta potential from 40 to $60 \mathrm{mV}$ are believed to be good stable, and those with more than $60 \mathrm{mV}$ have excellent stability. Kim et al. prepared Au nanofluids with an outstanding stability even after 1 month although no dispersants were observed [24]. The stability is due to a large negative zeta potential of $\mathrm{Au}$ nanoparticles in water. The influence of $\mathrm{pH}$ and sodium dodecylbenzene sulfonate (SDBS) on the stability of two water-based nanofluids was studied [25], and zeta potential analysis was an important technique to evaluate the stability. Zhu et al. [26] measured the zeta potential of $\mathrm{Al}_{2} \mathrm{O}_{3}-\mathrm{H}_{2} \mathrm{O}$ nanofluids under different $\mathrm{pH}$ values and different SDBS concentration. The Derjaguin-Laudau-VerweyOverbeek (DLVO) theory was used to calculate attractive and repulsive potentials. Cationic gemini surfactant as stabilizer was used to prepare stable water-based nanofluids containing MWNTs [27]. Zeta potential measurements were employed to study the absorption mechanisms of the surfactants on the MWNT surfaces with the help of Fourier transformation infrared spectra.

3.1.3. Spectral Absorbency Analysis. Spectral absorbency analysis is another efficient way to evaluate the stability of nanofluids. In general, there is a linear relationship between the absorbency intensity and the concentration of nanoparticles in fluid. Huang et al. evaluated the dispersion characteristics of alumina and copper suspensions using the conventional sedimentation method with the help of absorbency analysis by using a spectrophotometer after the suspensions deposited for $24 \mathrm{~h}$ [28]. The stability investigation of colloidal FePt nanoparticle systems was done via spectrophotometer analysis [29]. The sedimentation kinetics could also be determined by examining the absorbency of particle in solution [26].

If the nanomaterials dispersed in fluids have characteristic absorption bands in the wavelength $190-1100 \mathrm{~nm}$, it is an easy and reliable method to evaluate the stability of nanofluids using UV-vis spectral analysis. The variation of supernatant particle concentration of nanofluids with sediment time can be obtained by the measurement of absorption of nanofluids, because there is a linear relation between the supernatant nanoparticle concentration and the absorbance of suspended particles. The outstanding advantage comparing to other methods is that UV-vis spectral analysis can present the quantitative concentration of nanofluids. Hwang et al. [30] studied the stability of nanofluids with the UV-vis spectrophotometer. It was believed that the stability of nanofluids was strongly affected by the characteristics of the suspended particles and the base fluid such as particle morphology. Moreover, the 
addition of a surfactant could improve the stability of the suspensions. The relative stability of MWNT nanofluids [27] could be estimated by measuring the UV-vis absorption of the MWNT nanofluids at different sediment times. From the above relation between MWNT concentration and its UV-vis absorbance value, the concentration of the MWNT nanofluids at different sediment times could be obtained. The above three methods can be united to investigate the stability of nanofluids. For example, Li et al. evaluated the dispersion behavior of the aqueous copper nanosuspensions under different $\mathrm{pH}$ values, different dispersant type, and concentration by the method of zeta potential, absorbency, and sedimentation photographs [21].

\subsection{The Ways to Enhance the Stability of Nanofluids}

3.2.1. Surfactants Used in Nanofluids. Surfactants used in nanofluids are also called dispersants. Adding dispersants in the two-phase systems is an easy and economic method to enhance the stability of nanofluids. Dispersants can markedly affect the surface characteristics of a system in small quantity. Dispersants consists of a hydrophobic tail portion, usually a long-chain hydrocarbon, and a hydrophilic polar head group. Dispersants are employed to increase the contact of two materials, sometimes known as wettability. In a two-phase system, a dispersant tends to locate at the interface of the two phases, where it introduces a degree of continuity between the nanoparticles and fluids. According to the composition of the head, surfactants are divided into four classes: nonionic surfactants without charge groups in its head (include polyethylene oxide, alcohols, and other polar groups), anionic surfactants with negatively charged head groups (anionic head groups include long-chain fatty acids, sulfosuccinates, alkyl sulfates, phosphates, and sulfonates), cationic surfactants with positively charged head groups (cationic surfactants may be protonated long-chain amines and long-chain quaternary ammonium compounds), and amphoteric surfactants with zwitterionic head groups (charge depends on $\mathrm{pH}$. The class of amphoteric surfactants is represented by betaines and certain lecithins). How to select suitable dispersants is a key issue. In general, when the base fluid of nanofluids is polar solvent, we should select water-soluble surfactants; otherwise, we will select oilsoluble ones. For nonionic surfactants, we can evaluate the solubility through the term hydrophilic/lipophilic balance (HLB) value. The lower the HLB number, the more oilsoluble the surfactants, and in turn, the higher the HLB number, the more water-soluble the surfactants is. The HLB value can be obtained easily by many handbooks. Although surfactant addition is an effective way to enhance the dispersibility of nanoparticles, surfactants might cause several problems [31]. For example, the addition of surfactants may contaminate the heat transfer media. Surfactants may produce foams when heating, while heating and cooling are routine processes in heat exchange systems. Furthermore, surfactant molecules attaching on the surfaces of nanoparticles may enlarge the thermal resistance between the nanoparticles and the base fluid, which may limit the enhancement of the effective thermal conductivity.
3.2.2. Surface Modification Techniques: Surfactant-Free Method. Use of functionalized nanoparticles is a promising approach to achieve long-term stability of nanofluid. It represents the surfactant-free technique. Yang and Liu presented a work on the synthesis of functionalized silica $\left(\mathrm{SiO}_{2}\right)$ nanoparticles by grafting silanes directly to the surface of silica nanoparticles in original nanoparticle solutions [32]. One of the unique characteristics of the nanofluids was that no deposition layer formed on the heated surface after a pool boiling process. Hwang et al. introduced hydrophilic functional groups on the surface of the nanotubes by mechanochemical reaction [30]. The prepared nanofluids, with no contamination to medium, good fluidity, low viscosity, high stability, and high thermal conductivity, would have potential applications as coolants in advanced thermal systems. A wet mechanochemical reaction was applied to prepare surfactant-free nanofluids containing double- and single-walled CNTs. Results from the infrared spectrum and zeta potential measurements showed that the hydroxyl groups had been introduced onto the treated CNT surfaces [33]. The chemical modification to functionalize the surface of carbon nanotubes is a common method to enhance the stability of carbon nanotubes in solvents. Here, we present a review about the surface modification of carbon nanotubes [34]. Plasma treatment was used to modify the surface characteristics of diamond nanoparticles [35]. Through plasma treatment using gas mixtures of methane and oxygen, various polar groups were imparted on the surface of the diamond nanoparticles, improving their dispersion property in water. A stable dispersion of titania nanoparticles in an organic solvent of diethylene glycol dimethylether (diglyme) was successfully prepared using a ball milling process [36]. In order to enhance dispersion stability of the solution, surface modification of dispersed titania particles was carried out during the centrifugal bead mill process. Surface modification was utilized with silane coupling agents, (3-acryl-oxypropyl) trimethoxysilane and trimethoxypropylsilane. Zinc oxide nanoparticles could be modified by polymethacrylic acid (PMAA) in aqueous system [37]. The hydroxyl groups of nano-ZnO particle surface could interact with carboxyl groups of PMAA and form poly (zinc methacrylate) complex on the surface of nano-ZnO. PMAA enhanced the dispersibility of nano$\mathrm{ZnO}$ particles in water. The modification did not alter the crystalline structure of the $\mathrm{ZnO}$ nanoparticles.

3.2.3. Stability Mechanisms of Nanofluids. Particles in dispersion may adhere together and form aggregates of increasing size which may settle out due to gravity. Stability means that the particles do not aggregate at a significant rate. The rate of aggregation is in general determined by the frequency of collisions and the probability of cohesion during collision. Derjaguin, Verway, Landau, and Overbeek (DVLO) developed a theory which dealt with colloidal stability [38, 39]. DLVO theory suggests that the stability of a particle in solution is determined by the sum of van der Waals attractive and electrical double layer repulsive forces that exist between particles as they approach each other due to the Brownian motion they are undergoing. If the attractive force is larger 
TABLe 1: Properties of oxides and their nanofluids.

\begin{tabular}{lccccc}
\hline & $\begin{array}{c}\text { Thermal conductivity* } \\
\text { W/(m.K) }\end{array}$ & Density $\left(\mathrm{g} / \mathrm{cm}^{3}\right)$ & Crystalline & $\begin{array}{c}\text { Viscosity (Cp) with } \\
5.0 \text { vol. \% 30 }\end{array}$ & $\begin{array}{c}\text { Thermal conductivity } \\
\text { enhancement of nanofluids (\%) } \\
\text { with 5.0 vol. \% }\end{array}$ \\
\hline $\mathrm{MgO}$ & 48.4 & 2.9 & Cubic & 17.4 & 40.6 \\
$\mathrm{TiO}_{2}$ & 8.4 & 4.1 & Anatase & 31.2 & 27.2 \\
$\mathrm{ZnO}$ & 13.0 & 5.6 & Wurtzite & 129.2 & 26.8 \\
$\mathrm{Al}_{2} \mathrm{O}_{3}$ & 36.0 & 3.6 & $\gamma$ & 28.2 & 28.2 \\
$\mathrm{SiO}_{2}$ & 10.4 & 2.6 & noncrystalline & 31.5 & 25.3 \\
\hline
\end{tabular}

* Thermal conductivities of the oxides are for the corresponding bulk materials

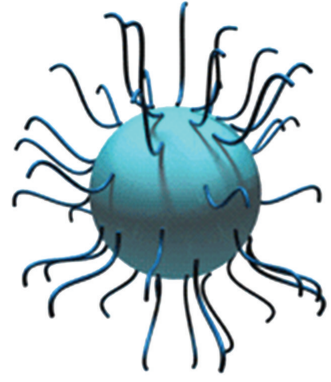

Steric stabilization

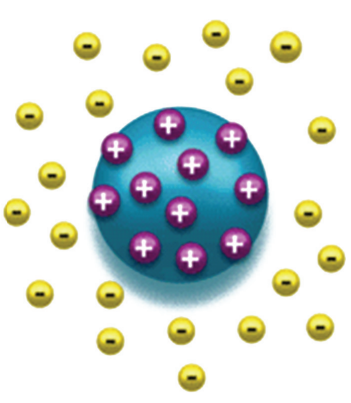

Electrostatic stabilization
FIgURE 2: Types of colloidal stabilization.

than the repulsive force, the two particles will collide, and the suspension is not stable. If the particles have a sufficient high repulsion, the suspensions will exist in stable state. For stable nanofluids or colloids, the repulsive forces between particles must be dominant. According to the types of repulsion, the fundamental mechanisms that affect colloidal stability are divided into two kinds, one is steric repulsion, and another is electrostatic (charge) repulsion, shown in Figure 2. For steric stabilization, polymers are always involved into the suspension system, and they will adsorb onto the particles surface, producing an additional steric repulsive force. For example, Zinc oxide nanoparticles modified by PMAA have good compatibility with polar solvents [37]. Silver nanofluids are very stable due to the protective role of PVP, as it retards the growth and agglomeration of nanoparticles by steric effect. PVP is an efficient agent to improve the stability of graphite suspension [22]. The steric effect of polymer dispersant is determined by the concentration of the dispersant. If the PVP concentration is low, the surface of the graphite particles is gradually coated by PVP molecules with the increase of PVP. Kamiya et al. studied the effect of polymer dispersant structure on electrosteric interaction and dense alumina suspension behavior [40]. An optimum hydrophilic to hydrophobic group ratio was obtained from the maximum repulsive force and minimum viscosity. For electrostatic stabilization, surface charge will be developed through one or more of the following mechanisms: (1) preferential adsorption of ions, (2) dissociation of surface charged species, (3) isomorphic substitution of ionsm, (4) accumulation or depletion of electrons at the surface, and (5) physical adsorption of charged species onto the surface.

\section{Application of Nanofluids}

4.1. Heat Transfer Intensification. Since the origination of the nanofluid concept about a decade ago, the potentials of nanofluids in heat transfer applications have attracted more and more attention. Up to now, there are some review papers which present overviews of various aspects of nanofluids [1, 3-6, 41-46], including preparation and characterization, techniques for the measurements of thermal conductivity, theory and model, thermophysical properties, and convective heat transfer. Our group studied the thermal conductivities of ethylene glycol- (EG-) based nanofluids containing oxides including $\mathrm{MgO}, \mathrm{TiO}_{2}, \mathrm{ZnO}, \mathrm{Al}_{2} \mathrm{O}_{3}$, and $\mathrm{SiO}_{2}$ nanoparticles [47], and the results (Table 1) demonstrated that MgO-EG nanofluid was found to have superior features with the highest thermal conductivity and lowest viscosity. In this part, we will summarize the applications of nanofluids in heat transfer enhancement.

4.1.1. Electronic Applications. Due to higher density of chips, design of electronic components with more compact makes heat dissipation more difficult. Advanced electronic devices face thermal management challenges from the high level of heat generation and the reduction of available surface area for heat removal. So, the reliable thermal management system is vital for the smooth operation of the advanced electronic devices. In general, there are two approaches to improve the heat removal for electronic equipment. One is to find an optimum geometry of cooling devices; another is to increase the heat transfer capacity. Nanofluids with higher thermal conductivities are predicated convective heat transfer coefficients compared to those of base fluids. Recent researches illustrated that nanofluids could increase the heat transfer coefficient by increasing the thermal conductivity of a coolant. Jang and Choi designed a new cooler, combined microchannel heat sink with nanofluids [48]. Higher cooling performance was obtained when compared to the device using pure water as working medium. Nanofluids reduced both the thermal resistance and the temperature difference between the heated microchannel wall and the coolant. A combined microchannel heat sink with nanofluids had the potential as the next-generation cooling devices for removing ultrahigh heat flux. Nguyen et al. designed a closed liquid-circuit to investigate the heat transfer enhancement of a liquid cooling system by replacing the base fluid (distilled water) with a nanofluid composed of distilled 
water and $\mathrm{Al}_{2} \mathrm{O}_{3}$ nanoparticles at various concentrations [49]. Measured data have clearly shown that the inclusion of nanoparticles within the distilled water has produced a considerable enhancement in convective heat transfer coefficient of the cooling block. With particle loading 4.5 vol\%, the enhancement is up to $23 \%$ with respect to that of the base fluid. It has also been observed that an augmentation of particle concentration has produced a clear decrease of the junction temperature between the heated component and the cooling block. Silicon microchannel heat sink performance using nanofluids containing $\mathrm{Cu}$ nanoparticles was analyzed [50]. It was found that nanofluids could enhance the performance as compared with that using pure water as the coolant. The enhancement was due to the increase in thermal conductivity of coolant and the nanoparticle thermal dispersion effect. The other advantage was that there was no extra pressure drop, since the nanoparticle was small, and particle volume fraction was low.

The thermal requirements on the personal computer become much stricter with the increase in thermal dissipation of CPU. One of the solutions is the use of heat pipes. Nanofluids, employed as working medium for conventional heat pipe, have shown higher thermal performances, having the potential as a substitute for conventional water in heat pipe. At a same charge volume, there is a significant reduction in thermal resistance of heat pipe with nanofluid containing gold nanoparticles as compared with water [51]. The measured results also show that the thermal resistance of a vertical meshed heat pipe varies with the size of gold nanoparticles. The suspended nanoparticles tend to bombard the vapor bubble during the bubble formation. Therefore, it is expected that the nucleation size of vapor bubble is much smaller for fluid with suspended nanoparticles than that without them. This may be the major reason for reducing the thermal resistance of heat pipe. Chen et al. studied the effect of a nanofluid on flat heat pipe (FHP) thermal performance [52], using silver nanofluid as the working fluid. The temperature difference and the thermal resistance of the FHP with the silver nanoparticle solution were lower than those with pure water. The plausible reasons for enhancement of the thermal performance of the FHP using the nanofluid can be explained by the critical heat flux enhancement by higher wettability and the reduction of the boiling limit. Nanofluid oscillating heat pipe with ultrahighperformance was developed by Ma et al. [53]. They combined nanofluids with thermally excited oscillating motion in an oscillating heat pipe, and heat transport capability significantly increased. For example, at the input power of 80.0 W, diamond nanofluid could reduce the temperature difference between the evaporator and the condenser from 40.9 to $24.3^{\circ} \mathrm{C}$. This study would accelerate the development of a highly efficient cooling device for ultrahigh-heat-flux electronic systems. The thermal performance investigation of heat pipe indicated that nanofluids containing silver or titanium nanoparticles could be used as an efficient cooling fluid for devices with high energy density. For a silver nanofluid, the temperature difference decreased $0.56-0.65$ compared to water at an input power of 30-50 W [54]. For the heat pipe with titanium nanoparticles at a volume concentration of $0.10 \%$, the thermal efficiency is $10.60 \%$ higher than that with the based working fluid [55]. These positive results are promoting the continued research and development of nanofluids for such applications.

4.1.2. Transportation. Nanofluids have great potentials to improve automotive and heavy-duty engine cooling rates by increasing the efficiency, lowering the weight and reducing the complexity of thermal management systems. The improved cooling rates for automotive and truck engines can be used to remove more heat from higher horsepower engines with the same size of cooling system. Alternatively, it is beneficial to design more compact cooling system with smaller and lighter radiators. It is, in turn, beneficial the high performance and high fuel economy of car and truck. Ethylene glycol-based nanofluids have attracted much attention in the application as engine coolant [56-58] due to the low-pressure operation compared with a 50/50 mixture of ethylene glycol and water, which is the nearly universally used automotive coolant. The nanofluids has a high boiling point, and it can be used to increase the normal coolant operating temperature and then reject more heat through the existing coolant system [59]. Kole et al. prepared car engine coolant $\left(\mathrm{Al}_{2} \mathrm{O}_{3}\right.$ nanofluid) using a standard car engine coolant (HP KOOLGARD) as the base fluid [60] and studied the thermal conductivity and viscosity of the coolant. The prepared nanofluid, containing only $3.5 \%$ volume fraction of $\mathrm{Al}_{2} \mathrm{O}_{3}$ nanoparticles, displayed a fairly higher thermal conductivity than the base fluid, and a maximum enhancement of $10.41 \%$ was observed at room temperature. Tzeng et al. [61] applied nanofluids to the cooling of automatic transmissions. The experimental platform was the transmission of a four-wheel drive vehicle. The used nanofluids were prepared by dispersing $\mathrm{CuO}$ and $\mathrm{Al}_{2} \mathrm{O}_{3}$ nanoparticles into engine transmission oil. The results showed that $\mathrm{CuO}$ nanofluids produced the lower transmission temperatures both at high and low rotating speeds. From the thermal performance viewpoint, the use of nanofluid in the transmission has a clear advantage.

The researchers of Argonne National Laboratory have assessed the applications of nanofluids for transportation [62]. The use of high-thermal conductive nanofluids in radiators can lead to a reduction in the frontal area of the radiator up to $10 \%$. The fuel saving is up to $5 \%$ due to the reduction in aerodynamic drag. It opens the door for new aerodynamic automotive designs that reduce emissions by lowering drag. The application of nanofluids also contributed to a reduction of friction and wear, reducing parasitic losses, operation of components such as pumps and compressors, and subsequently leading to more than $6 \%$ fuel savings. In fact, nanofluids not only enhance the efficiency and economic performance of car engine, but also will greatly influence the structure design of automotives. For example, the engine radiator cooled by a nanofluid will be smaller and lighter. It can be placed elsewhere in the vehicle, allowing for the redesign of a far more aerodynamic chassis. By reducing the size and changing the location of the radiator, a reduction in weight and wind resistance could enable greater fuel efficiency and subsequently lower exhaust 
emissions. Computer simulations from the US department of energy's office of vehicle technology showed that nanofluid coolants could reduce the size of truck radiators by $5 \%$. This would result in a $2.5 \%$ fuel saving at highway speeds.

The practical applications are on the road. In USA, car manufacturers GM and Ford are running their own research programs on nanofluid applications. A $€ 8.3$ million FP7 project, named NanoHex (Nanofluid Heat Exchange), began to run. It involved 12 organizations from Europe and Israel ranging from Universities to SMEs and major companies. NanoHex is overcoming the technological challenges faced in development and application of reliable and safe nanofluids for more sophisticated, energy efficient, and environmentally friendly products and services [63].

4.1.3. Industrial Cooling Applications. The application of nanofluids in industrial cooling will result in great energy savings and emissions reductions. For US industry, the replacement of cooling and heating water with nanofluids has the potential to conserve 1 trillion Btu of energy $[41,64]$. For the US electric power industry, using nanofluids in closed loop cooling cycles could save about 10-30 trillion Btu per year (equivalent to the annual energy consumption of about 50,000-150,000 households). The associated emissions reductions would be approximately 5.6 million metric tons of carbon dioxide, 8,600 metric tons of nitrogen oxides, and 21,000 metric tons of sulfur dioxide [65].

Experiments were performed using a flow-loop apparatus to explore the performance of polyalphaolefin nanofluids containing exfoliated graphite nanoparticle fibers in cooling [66]. It was observed that the specific heat of nanofluids was found to be $50 \%$ higher for nanofluids compared with polyalphaolefin, and it increased with temperature. The thermal diffusivity was found to be 4 times higher for nanofluids. The convective heat transfer was enhanced by $10 \%$ using nanofluids compared with using polyalphaolefin. $\mathrm{Ma}$ et al. proposed the concept of nanoliquid-metal fluid, aiming to establish an engineering route to make the highest conductive coolant with about several dozen times larger thermal conductivity than that of water [45]. The liquid metal with low melting point is expected to be an idealistic base fluid for making superconductive solution, which may lead to the ultimate coolant in a wide variety of heat transfer enhancement area. The thermal conductivity of the liquidmetal fluid can be enhanced through the addition of more conductive nanoparticles.

4.1.4. Heating Buildings and Reducing Pollution. Nanofluids can be applied in the building heating systems. Kulkarni et al. evaluated how they perform heating buildings in cold regions [67]. In cold regions, it is a common practice to use ethylene or propylene glycol mixed with water in different proportions as a heat transfer fluid. So, 60:40 ethylene glcol/water (by weight) was selected as the base fluid. The results showed that using nanofluids in heat exchangers could reduce volumetric and mass flow rates, resulting in an overall pumping power savings. Nanofluids necessitate smaller heating systems, which are capable of delivering the same amount of thermal energy as larger heating systems but are less expensive. This lowers the initial equipment cost excluding nanofluid cost. This will also reduce environmental pollutants, because smaller heating units use less power, and the heat transfer unit has less liquid and material waste to discard at the end of its life cycle.

4.1.5. Nuclear Systems Cooling. The Massachusetts Institute of Technology has established an interdisciplinary center for nanofluid technology for the nuclear energy industry. The researchers are exploring the nuclear applications of nanofluids, specifically the following three [68]: (1) main reactor coolant for pressurized water reactors (PWRs). It could enable significant power uprates in current and future PWRs, thus enhancing their economic performance. Specifically, the use of nanofluids with at least 32\% higher critical heat flux (CHF) could enable a $20 \%$ power density uprate in current plants without changing the fuel assembly design and without reducing the margin to CHF; (2) coolant for the emergency core cooling systems (ECCSs) of both PWRs and boiling water reactors. The use of a nanofluid in the ECCS accumulators and safety injection can increase the peak-cladding-temperature margins (in the nominal-power core) or maintain them in uprated cores if the nanofluid has a higher post-CHF heat transfer rate; (3) coolant for invessel retention of the molten core during severe accidents in high-power-density light water reactors. It can increase the margin to vessel breach by $40 \%$ during severe accidents in high-power density systems such as Westinghouse APR1000 and the Korean APR1400. While there exist several significant gaps, including the nanofluid thermal-hydraulic performance at prototypical reactor conditions and the compatibility of the nanofluid chemistry with the reactor materials. Much work should be done to overcome these gaps before any applications can be implemented in a nuclear power plant.

4.1.6. Space and Defense. Due to the restriction of space, energy, and weight in space station and aircraft, there is a strong demand for high efficient cooling system with smaller size. You et al. [69] and Vassalo et al. [70] have reported order of magnitude increases in the critical heat flux in pool boiling with nanofluids compared to the base fluid alone. Further research of nanofluids will lead to the development of next generation of cooling devices that incorporate nanofluids for ultrahigh-heat-flux electronic systems, presenting the possibility of raising chip power in electronic components or simplifying cooling requirements for space applications. A number of military devices and systems require high-heat flux cooling to the level of tens of $\mathrm{MW} / \mathrm{m}^{2}$. At this level, the cooling of military devices and system is vital for the reliable operation. Nanofluids with high critical heat fluxes have the potential to provide the required cooling in such applications as well as in other military systems, including military vehicles, submarines, and high-power laser diodes. Therefore, nanofluids have wide application in space and defense fields, where power density is very high and the components should be smaller and weight less. 
4.2. Mass Transfer Enhancement. Several researches have studied the mass transfer enhancement of nanofluids. Kim et al. initially examined the effect of nanoparticles on the bubble type absorption for $\mathrm{NH}_{3} / \mathrm{H}_{2} \mathrm{O}$ absorption system [71]. The addition of nanoparticles enhances the absorption performance up to 3.21 times. Then, they visualized the bubble behavior during the $\mathrm{NH}_{3} / \mathrm{H}_{2} \mathrm{O}$ absorption process and studied the effect of nanoparticles and surfactants on the absorption characteristics [72]. The results show that the addition of surfactants and nanoparticles improved the absorption performance up to 5.32 times. The addition of both surfactants and nanoparticles enhanced significantly the absorption performance during the ammonia bubble absorption process. The theoretical investigations of thermodiffusion and diffusionthermo on convective instabilities in binary nanofluids for absorption application were conducted. Mass diffusion is induced by thermal gradient. Diffusionthermo implies that heat transfer is induced by concentration gradient [73]. Ma et al. studied the mass transfer process of absorption using CNTs-ammonia nanofluids as the working medium $[74,75]$. The absorption rates of the CNTs-ammonia binary nanofluids were higher than those of ammonia solution without CNTs. The effective absorption ratio of the CNTs-ammonia binary nanofluids increased with the initial concentration of ammonia and the mass fraction of CNTs. Komati et al. studied $\mathrm{CO}_{2}$ absorption into amine solutions, and the addition of ferrofluids increased the mass transfer coefficient in gas/liquid mass transfer [76], and the enhancement extent depended on the amount of ferrofluid added. The enhancement in mass transfer coefficient was $92.8 \%$ for a volume fraction of the fluid of about $50 \%$ (solid magnetite volume fraction of about $0.39 \%$ ). The research about the influence of $\mathrm{Al}_{2} \mathrm{O}_{3}$ nanofluid on the falling film absorption with ammonia water showed that the sorts of nanoparticles and surfactants in the nanofluid and the concentration of ammonia in the basefluid were the key parameters influencing the absorption effect of ammonia [77].

So far, the mechanism leading to mass transfer enhancement is still unclear. The existing research work on the mass transfer in nanofluids is not enough. Much experimental and simulation work should be carried out to clarify some important influencing factors.

4.3. Energy Applications. For energy applications of nanofluids, two remarkable properties of nanofluids are utilized, one is the higher thermal conductivities of nanofluids, enhancing the heat transfer, another is the absorption properties of nanofluids.

4.3.1. Energy Storage. The temporal difference of energy source and energy needs made necessary the development of storage system. The storage of thermal energy in the form of sensible and latent heat has become an important aspect of energy management with the emphasis on efficient use and conservation of the waste heat and solar energy in industry and buildings [78]. Latent heat storage is one of the most efficient ways of storing thermal energy. Wu et al. evaluated the potential of $\mathrm{Al}_{2} \mathrm{O}_{3}-\mathrm{H}_{2} \mathrm{O}$ nanofluids as a new phase change material (PCM) for the thermal energy storage of cooling systems. The thermal response test showed the addition of $\mathrm{Al}_{2} \mathrm{O}_{3}$ nanoparticles remarkably decreased the supercooling degree of water, advanced the beginning freezing time, and reduced the total freezing time. Only adding $0.2 \mathrm{wt} \%$ $\mathrm{Al}_{2} \mathrm{O}_{3}$ nanoparticles, the total freezing time of $\mathrm{Al}_{2} \mathrm{O}_{3}-\mathrm{H}_{2} \mathrm{O}$ nanofluids could be reduced by $20.5 \%$. Liu et al. prepared a new sort of nanofluid phase change materials (PCMs) by suspending small amount of $\mathrm{TiO}_{2}$ nanoparticles in saturated $\mathrm{BaCl}_{2}$ aqueous solution [79]. The nanofluids PCMs possessed remarkably high thermal conductivities compared to the base material. The cool storage/supply rate and the cool storage/supply capacity all increased greatly than those of $\mathrm{BaCl}_{2}$ aqueous solution without added nanoparticles. The higher thermal performances of nanofluids PCMs indicate that they have a potential for substituting conventional PCMs in cool storage applications. Copper nanoparticles are efficient additives to improve the heating and cooling rates of PCMs [80]. For composites with $1 \mathrm{wt} \%$ copper nanoparticle, the heating and cooling times could be reduced by 30.3 and $28.2 \%$, respectively. The latent heats and phase-change temperatures changed very little after 100 thermal cycles.

4.3.2. Solar Absorption. Solar energy is one of the best sources of renewable energy with minimal environmental impact. The conventional direct absorption solar collector is a well-established technology, and it has been proposed for a variety of applications such as water heating; however, the efficiency of these collectors is limited by the absorption properties of the working fluid, which is very poor for typical fluids used in solar collectors. Recently, this technology has been combined with the emerging technologies of nanofluids and liquid-nanoparticle suspensions to create a new class of nanofluid-based solar collectors. Otanicar et al. reported the experimental results on solar collectors based on nanofluids made from a variety of nanoparticles (CNTs, graphite, and silver) [81]. The efficiency improvement was up to $5 \%$ in solar thermal collectors by utilizing nanofluids as the absorption media. In addition, they compared the experimental data with a numerical model of a solar collector with direct absorption nanofluids. The experimental and numerical results demonstrated an initial rapid increase in efficiency with volume fraction, followed by a leveling off in efficiency as volume fraction continues to increase. Theoretical investigation on the feasibility of using a nonconcentrating direct absorption solar collector showed that the presence of nanoparticles increased the absorption of incident radiation by more than nine times over that of pure water [82]. Under the similar operating conditions, the efficiency of an absorption solar collector using nanofluid as the working fluid was found to be up to $10 \%$ higher (on an absolute basis) than that of a flat-plate collector. Otanicar and Golden evaluated the overall economic and environmental impacts of the technology in contrast with conventional solar collectors using the life-cycle assessment methodology [83]. Results showed that for the current cost of nanoparticles the nanofluid-based solar collector had a slightly longer payback period but at the end of its useful life has the 
same economic saving as a conventional solar collector. Sani et al. investigated the optical and thermal properties of nanofluids consisting of aqueous suspensions of single-wall carbon nanohorns [84]. The observed nanoparticle-induced differences in optical properties appeared promising, leading to a considerably higher sunlight absorption. Both these effects, together with the possible chemical functionalization of carbon nanohorns, make this new kind of nanofluids very interesting for increasing the overall efficiency of the sunlight exploiting device.

4.4. Mechanical Applications. Why nanofluids have great friction reduction properties? Nanoparticles in nanofluids form a protective film with low hardness and elastic modulus on the worn surface can be considered as the main reason that some nanofluids exhibit excellent lubricating properties.

Magnetic fluids are kinds of special nanofluids. Magnetic liquid rotary seals operate with no maintenance and extremely low leakage in a very wide range of applications, and it utilizing the property magnetic properties of the magnetic nanoparticles in liquid.

4.4.1. Friction Reduction. Advanced lubricants can improve productivity through energy saving and reliability of engineered systems. Tribological research heavily emphasizes reducing friction and wear. Nanoparticles have attracted much interest in recent years due to their excellent loadcarrying capacity, good extreme pressure and friction reducing properties. Zhou et al. evaluated the tribological behavior of $\mathrm{Cu}$ nanoparticles in oil on a four-ball machine. The results showed that $\mathrm{Cu}$ nanoparticles as an oil additive had better friction-reduction and antiwear properties than zinc dithiophosphate, especially at high applied load. Meanwhile, the nanoparticles could also strikingly improve the loadcarrying capacity of the base oil [85]. Dispersion of solid particles was found to play an important role, especially when a slurry layer was formed. Water-based $\mathrm{Al}_{2} \mathrm{O}_{3}$ and diamond nanofluids were applied in the minimum quantity lubrication (MQL) grinding process of cast iron. During the nanofluid MQL grinding, a dense and hard slurry layer was formed on the wheel surface and could benefit the grinding performance. Nanofluids showed the benefits of reducing grinding forces, improving surface roughness, and preventing workpiece burning. Compared to dry grinding, MQL grinding could significantly reduce the grinding temperature [86]. Wear and friction properties of surface modified $\mathrm{Cu}$ nanoparticles, as 50CC oil additive were studied. The higher the oil temperature applied, the better the tribological properties of $\mathrm{Cu}$ nanoparticles were. It could be inferred that a thin copper protective film with lower elastic modulus and hardness was formed on the worn surface, which resulted in the good tribological performances of $\mathrm{Cu}$ nanoparticles, especially when the oil temperature was higher [87]. Yu et al. firstly reported that room temperature ionic liquid multiwalled carbon nanotubes composite was evaluated as lubricant additive in ionic liquid due to their excellent dispersibility and that the composite showed good frictionreduction and antiwear properties in friction process [88].
Wang et al. studied the tribological properties of ionic liquidbased nanofluids containing functionalized MWNTs under loads in the range of $200-800 \mathrm{~N}$ [89], indicating that the nanofluids exhibited preferable friction-reduction properties under $800 \mathrm{~N}$ and remarkable antiwear properties with use of reasonable concentrations. Magnetic nanoparticle $\mathrm{Mn}_{0.78} \mathrm{Zn}_{0.22} \mathrm{Fe}_{2} \mathrm{O}_{4}$ was also an efficient lubricant additive. When used as a lubricant additive in 46 turbine oil, it could improve the wear resistance, load-carrying capacity, and antifriction ability of base oil, and the decreasing percentage of wear scar diameter was $25.45 \%$ compared to the base oil. This was a typical self-repair phenomenon [90]. Chen et al. reported on dispersion stability enhancement and selfrepair principle discussion of ultrafine-tungsten disulfide in green lubricating oil [91]. Ultrafine-tungsten disulfide particulates could fill and level up the furrows on abrasive surfaces, repairing abrasive surface well. What is more, ultrafine-tungsten disulfide particulates could form a $\mathrm{WS}_{2}$ film with low shear stress by adsorbing and depositing in the hollowness of abrasive surface, making the abrasive surface be more smooth, and the FeS film formed in tribochemical reaction could protect the abrasive surface further, all of which realize the self-repair to abrasive surface. The tribological properties of liquid paraffin with $\mathrm{SiO}_{2}$ nanoparticles additive made by a sol-gel method was investigated by Peng et al. [92]. The optimal concentrations of $\mathrm{SiO}_{2}$ nanoparticles in liquid paraffin was associated with better tribological properties than pure paraffin oil, and an antiwear ability that depended on the particle size, and oleic acid surface-modified $\mathrm{SiO}_{2}$ nanoparticles with an average diameter of $58 \mathrm{~nm}$ provided better tribological properties in load-carrying capacity, antiwear and friction-reduction than pure liquid paraffin. Nanoparticles can easily penetrate into the rubbing surfaces because of their nanoscale. During the frictional process, the thin physical tribofilm of the nanoparticles forms between rubbing surfaces, which cannot only bear the load, but also separates the rubbing surfaces. The spherical $\mathrm{SiO}_{2}$ nanoparticles could roll between the rubbing surfaces in sliding friction, and the originally pure sliding friction becomes mixed sliding and rolling friction. Therefore, the friction coefficient declines markedly and then remains constant.

4.4.2. Magnetic Sealing. Magnetic fluids (ferromagnetic fluid) are kinds of special nanofluids. They are stable colloidal suspensions of small magnetic particles such as magnetite $\left(\mathrm{Fe}_{3} \mathrm{O}_{4}\right)$. The properties of the magnetic nanoparticles, the magnetic component of magnetic nanofluids, may be tailored by varying their size and adapting their surface coating in order to meet the requirements of colloidal stability of magnetic nanofluids with nonpolar and polar carrier liquids [93]. Comparing with the mechanical sealing, magnetic sealing offers a cost-effective solution to environmental and hazardous-gas sealing in a wide variety of industrial rotation equipment with high-speed capability, low-friction power losses, and long life and high reliability [94]. A ring magnet forms part of a magnetic circuit in which an intense magnetic field is established in the gaps between the teeth on a magnetically permeable shaft and the 
surface of an opposing pole block. Ferrofluid introduced into the gaps forms discrete liquid rings capable of supporting a pressure difference while maintaining zero leakage. The seals operate without wear as the shaft rotates, because the mechanical moving parts do not touch. With these unique characteristics, sealing liquids with magnetic fluids can be applied in many application areas. It is reported that an iron particle dispersed magnetic fluids was utilized in the sealing of a high-rotation pump. The sealing holds pressure of $618 \mathrm{kPa}$ with a $1800 \mathrm{r} / \mathrm{min}$ [95]. Mitamura et al. studied the application of a magnetic fluid seal to rotary blood pumps. The developed magnetic fluid seal worked for over 286 days in a continuous flow condition, for 24 days (ongoing) in a pulsatile flow condition and for $24 \mathrm{~h}$ (electively terminated) in blood flow [96]. Ferrocobalt magnetic fluid was used for oil sealing, and the holding pressure is 25 times as high as that of a conventional magnetite sealing [97].

4.5. Biomedical Application. For some special kinds of nanoparticles, they have antibacterial activities or drug-delivery properties, so the nanofluids containing these nanoparticles will exhibit some relevant properties.

4.5.1. Antibacterial Activity. Organic antibacterial materials are often less stable particularly at high temperatures or pressures. As a consequence, inorganic materials such as metal and metal oxides have attracted lots of attention over the past decade due to their ability to withstand harsh process conditions. The antibacterial behaviour of $\mathrm{ZnO}$ nanofluids shows that the $\mathrm{ZnO}$ nanofluids have bacteriostatic activity against [98]. Electrochemical measurements suggest some direct interaction between $\mathrm{ZnO}$ nanoparticles and the bacteria membrane at high $\mathrm{ZnO}$ concentrations. Jalal et al. prepared $\mathrm{ZnO}$ nanoparticles via a green method. The antibacterial activity of suspensions of $\mathrm{ZnO}$ nanoparticles against Escherichia coli (E. coli) has been evaluated by estimating the reduction ratio of the bacteria treated with $\mathrm{ZnO}$. Survival ratio of bacteria decreases with increasing the concentrations of $\mathrm{ZnO}$ nanofluids and time [99]. Further investigations have clearly demonstrated that $\mathrm{ZnO}$ nanoparticles have a wide range of antibacterial effects on a number of other microorganisms. The antibacterial activity of $\mathrm{ZnO}$ may be dependent on the size and the presence of normal visible light [100]. Recent research showed that $\mathrm{ZnO}$ nanoparticles exhibited impressive antibacterial properties against an important foodborne pathogen, E. coli O157:H7, and the inhibitory effects increased as the concentrations of $\mathrm{ZnO}$ nanoparticles increased. $\mathrm{ZnO}$ nanoparticles changed the cell membrane components including lipids and proteins. $\mathrm{ZnO}$ nanoparticles could distort bacterial cell membrane, leading to loss of intracellular components, and ultimately the death of cells, considered as an effective antibacterial agent for protecting agricultural and food safety [101].

The antibacterial activity research of $\mathrm{CuO}$ nanoparticles showed that they possessed antibacterial activity against four bacterial strains. The size of nanoparticles was less than that of the pore size in the bacteria, and thus, they had a unique property of crossing the cell membrane without any hindrance. It could be hypothesized that these nanoparticles formed stable complexes with vital enzymes inside cells which hampered cellular functioning resulting in their death [102]. Bulk equivalents of these products showed no inhibitory activity, indicating that particle size was determinant in activity [103]. Lee et al. reported the antibacterial efficacy of nanosized silver colloidal solution on the cellulosic and synthetic fabrics [104]. The antibacterial treatment of the textile fabrics was easily achieved by padding them with nanosized silver colloidal solution. The antibacterial efficacy of the fabrics was maintained after many times laundering. Silver colloid is an efficient antibacterial agent. The silver colloid prepared by a one-step synthesis showed high antimicrobial and bactericidal activity against Gram-positive and Gram-negative bacteria, including highly multiresistant strains such as methicillin-resistant staphylococcus aureus. The antibacterial activity of silver nanoparticles was found to be dependent on the size of silver particles. A very low concentration of silver gave antibacterial performance [105]. The aqueous suspensions of fullerenes and nano- $\mathrm{TiO}_{2}$ can produce reactive oxygen species (ROS). Bacterial (E. coli) toxicity tests suggested that unlike nano- $\mathrm{TiO}_{2}$ which was exclusively phototoxic, the antibacterial activity of fullerene suspensions was linked to ROS production. Nano- $\mathrm{TiO}_{2}$ may be more efficient for water treatment involving UV or solar energy, to enhance contaminant oxidation and perhaps for disinfection. However, fullerol and $\mathrm{PVP} / \mathrm{C}_{60}$ may be useful as water treatment agents targeting specific pollutants or microorganisms that are more sensitive to either superoxide or singlet oxygen [106]. Lyon and Alvarez proposed that $\mathrm{C}_{60}$ suspensions exerted ROS-independent oxidative stress in bacteria, with evidence of protein oxidation, changes in cell membrane potential, and interruption of cellular respiration. This mechanism requires direct contact between the nanoparticle and the bacterial cell and differs from previously reported nanomaterial antibacterial mechanisms that involve ROS generation (metal oxides) or leaching of toxic elements (nanosilver) [107].

4.5.2. Nanodrug Delivery. Over the last few decades, colloidal drug delivery systems have been developed in order to improve the efficiency and the specificity of drug action [108]. The small-size, customized surface improved solubility, and multifunctionality of nanoparticles opens many doors and creates new biomedical applications. The novel properties of nanoparticles offer the ability to interact with complex cellular functions in new ways [109]. Gold nanoparticles provide nontoxic carriers for drug- and gene-delivery applications. With these systems, the gold core imparts stability to the assembly, while the monolayer allows tuning of surface properties such as charge and hydrophobicity. Another attractive feature of gold nanoparticles is their interaction with thiols, providing an effective and selective means of controlled intracellular release [110]. Nakano et al. proposed the drug-delivery system using nanomagnetic fluid [111], which targeted and concentrated drugs using a ferrofluid cluster composed of magnetic nanoparticles. The potential of magnetic nanoparticles stems from the intrinsic properties of their magnetic cores combined with their drug-loading capability and the biochemical properties 
that can be bestowed on them by means of a suitable coating. CNT has emerged as a new alternative and efficient tool for transporting and translocating therapeutic molecules. CNT can be functionalised with bioactive peptides, proteins, nucleic acids, and drugs and used to deliver their cargos to cells and organs. Because functionalised CNT display low toxicity and are not immunogenic, such systems hold great potential in the field of nanobiotechnology and nanomedicine $[112,113]$. Pastorin et al. have developed a novel strategy for the functionalisation of CNTs with two different molecules using the 1,3-dipolar cycloaddition of azomethine ylides [114]. The attachment of molecules that will target specific receptors on tumour cells will help improve the response to anticancer agents. Liu et al. have found that prefunctionalized CNTs can adsorb widely used aromatic molecules by simple mixing, forming "forestscrub"-like assemblies on CNTs with PEG extending into water to impart solubility and aromatic molecules densely populating CNT sidewalls. The work establishes a novel, easy-to-make formulation of a SWNT-doxorubicin complex with extremely high drug loading efficiency [115].

In recent years, graphene based drug delivery systems have attracted more and more attention. In 2008, Sun et al. firstly reported the application of nanographene oxide (NGO) for cellular imaging and drug delivery [116]. They have developed functionalization chemistry in order to impart solubility and compatibility of NGO in biological environments. Simple physicosorption via $\pi$-stacking can be used for loading doxorubicin, a widely used cancer drug onto NGO functionalized with antibody for selective killing of cancer cells in vitro. Functional nanoscale graphene oxide is found to be a novel nanocarrier for the loading and targeted delivery of anticancer drugs [117]. Controlled loading of two anticancer drugs onto the folic acid-conjugated NGO via $\pi-\pi$ stacking and hydrophobic interactions demonstrated that NGO loaded with the two anticancer drugs showed specific targeting to MCF-7 cells (human breast cancer cells with folic acid receptors), and remarkably high cytotoxicity compared to NGO loaded with either doxorubicin or camptothecin only. The PEGylated (PEG: polyethylene glycol) nanographene oxide could be used for the delivery of water-insoluble cancer drugs [118]. PEGylated NGO readily complexes with a water-insoluble aromatic molecule SN38, a camptothecin analogue, via noncovalent van der Waals interaction. The NGO-PEG-SN38 complex exhibits excellent aqueous solubility and retains the high potency of free SN38 dissolved in organic solvents. Yang et al. found GO- $\mathrm{Fe}_{3} \mathrm{O}_{4}$ hybrid could be loaded with anticancer drug doxorubicin hydrochloride with a high loading capacity [119]. This $\mathrm{GO}-\mathrm{Fe}_{3} \mathrm{O}_{4}$ hybrid showed superparamagnetic property and could congregate under acidic conditions and be redispersed reversibly under basic conditions. This $\mathrm{pH}-$ triggered controlled magnetic behavior makes this material a promising candidate for controlled targeted drug delivery.

\subsection{Other Applications}

4.6.1. Intensify Microreactors. The discovery of high enhancement of heat transfer in nanofluids can be applicable to the area of process intensification of chemical reactors through integration of the functionalities of reaction and heat transfer in compact multifunctional reactors. Fan et al. studied a nanofluid based on benign $\mathrm{TiO}_{2}$ material dispersed in ethylene glycol in an integrated reactorheat exchanger [120]. The overall heat transfer coefficient increase was up to $35 \%$ in the steady state continuous experiments. This resulted in a closer temperature control in the reaction of selective reduction of an aromatic aldehyde by molecular hydrogen and very rapid change in the temperature of reaction under dynamic reaction control.

4.6.2. Nanofluids as Vehicular Brake Fluids. A vehicle's kinetic energy is dispersed through the heat produced during the process of braking and this is transmitted throughout the brake fluid in the hydraulic braking system [39], and now, there is a higher demand for the properties of brake oils. Copper-oxide and aluminum-oxide based brake nanofluids were manufactured using the arc-submerged nanoparticle synthesis system and the plasma charging arc system, respectively [121, 122]. The two kinds of nanofluids both have enhanced properties such as a higher boiling point, higher viscosity, and a higher conductivity than that of traditional brake fluid. By yielding a higher boiling point, conductivity, and viscosity, the nanofluid brake oil will reduce the occurrence of vapor-lock and offer increased safety while driving.

4.6.3. Nanofluids-Based Microbial Fuel Cell. Microbial fuel cells (MFC) that utilize the energy found in carbohydrates, proteins, and other energy-rich natural products to generate electrical power have a promising future. The excellent performance of MFC depends on electrodes and electron mediator. Sharma et al. constructed a novel microbial fuel cell (MFC) using novel electron mediators and CNTbased electrodes [123]. The novel mediators are nanofluids which were prepared by dispersing nanocrystalline platinum anchored CNTs in water. They compared the performance of the new E. coli-based MFC to the previously reported E. coli-based microbial fuel cells with neutral red and methylene blue electron mediators. The performance of the MFC using CNT-based nanofluids and CNT-based electrodes has been compared against plain graphite electrodebased MFC. CNT-based electrodes showed as high as $\sim 6-$ fold increase in the power density compared to graphite electrodes. The work demonstrates the potential of noble metal nanoparticles dispersed on CNT-based MFC for the generation of high energies from even simple bacteria like E. coli.

4.6.4. Nanofluids with Unique Optical Properties. Optical filters are used to select different wavelengths of light. The ferrofluid-based optical filter has tunable properties. The desired central wavelength region can be tuned by an external magnetic field. Philip et al. developed a ferrofluid-based emulsion for selecting different bands of wavelengths in the UV, visible, and IR regions [124]. The desired range 
$q$
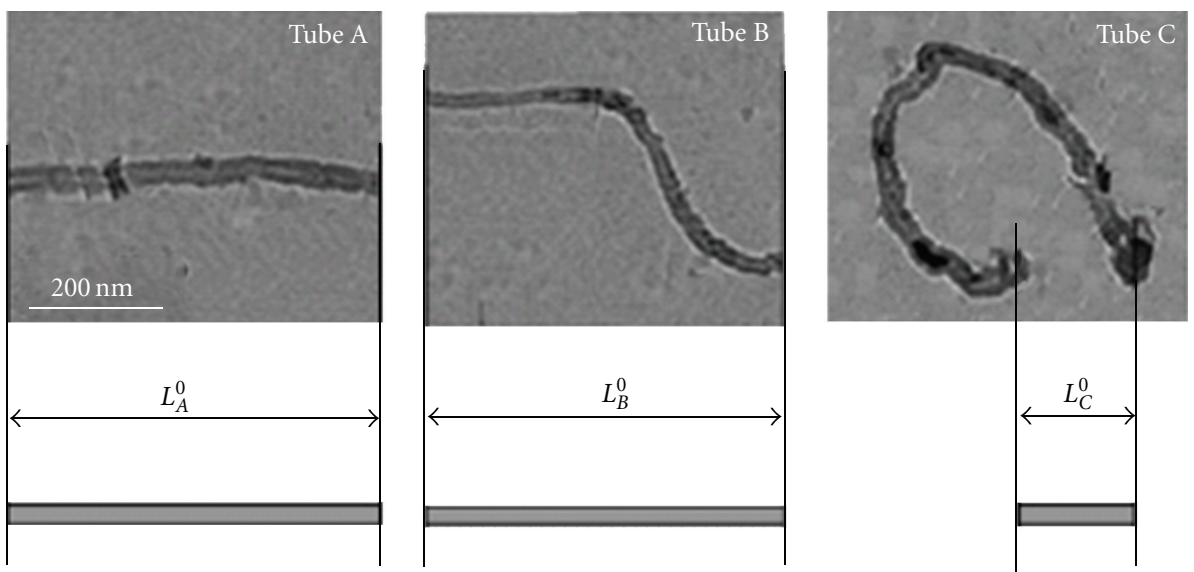

Figure 3: Actual nonstraight CNTs (left two) and equivalent straight thermal passages (right).

of wavelengths, bandwidth, and percentage of reflectivity could be easily controlled by using suitably tailored ferrofluid emulsions. Mishra et al. developed nanofluids with selective visible colors in gold nanoparticles embedded in polymer molecules of polyvinyl pyrrolidone (PVP) in water [125]. They compared the developments in the apparent visible colors in forming the Au-PVP nanofluids of 0.05, 0.10, 0.50 , and $1.00 \mathrm{wt} \%$ Au contents. The surface plasmon bands, which occurs over $480-700 \mathrm{~nm}$, varies sensitively in its position as well as the intensity when varying the Au content $0-1 \mathrm{wt} \%$.

\section{Conclusions and Future Work}

Many interesting properties of nanofluids have been reported in the past decades. This paper presents an overview of the recent developments in the study of nanofluids, including the preparation methods, the evaluation methods for their stability, the ways to enhance their stability, the stability mechanisms, and their potential applications in heat transfer intensification, mass transfer enhancement, energy fields, mechanical fields, biomedical fields, and so forth.

Although nanofluids have displayed enormously exciting potential applications, some vital hinders also exist before commercialization of nanofluids. The following key issues should receive greater attention in the future. Firstly, further experimental and theoretical research is required to find the major factors influencing the performance of nanofluids. Up to now, there is a lack of agreement between experimental results from different groups, so it is important to systematically identify these factors. The detailed and accurate structure characterizations of the suspensions may be the key to explain the discrepancy in the experimental data. Secondly, increase in viscosity by the use of nanofluids is an important drawback due to the associated increase in pumping power. The applications for nanofluids with low viscosity and high conductivity are promising. Enhancing the compatibility between nanomaterials and the base fluids through modifying the interface properties of two phases may be one of the solution routes. Thirdly, the shape of the additives in nanofluids is very important for the properties; therefore, the new nanofluid synthesis approaches with controllable microscope structure will be an interesting research work. Fourthly, stability of the suspension is a crucial issue for both scientific research and practical applications. The stability of nanofluids, especially the longterm stability, the stability in the practical conditions, and the stability after thousands of thermal cycles should be paid more attention. Fifthly, there is a lack of investigation of the thermal performance of nanofluids at high temperatures, which may widen the possible application areas of nanofluids, like in high-temperature solar energy absorption and high-temperature energy storage. At the same time, high temperature may accelerate the degradation of the surfactants used as dispersants in nanofluids and may produce more foams. These factors should be taken into account. Finally, the properties of nanofluids strongly depend on the shape and property of the additive. Xie's findings indicated that thermal conductivity enhancement was adjusted by ball milling and cutting the treated CNTs suspended in the nanofluids to relatively straight CNTs with an appropriate length distribution. They proposed the concept of straightness ratio to explain the facts (Figure 3 ). Nanofluid research can be enrichened and extended through exploring new nanomaterials. For example, the newly discovered 2D monatomic sheet graphene is a promising candidate material to enhance the thermal conductivity of the base fluid [126, 127], as shown in Figure 4. The concept of nanofluids is extended by the use of phase change materials, which goes well beyond simply increasing the thermal conductivity of a fluid [128]. It is found that the indium/polyalphaolefin phase change nanofluid exhibits simultaneously enhanced thermal conductivity and specific heat. 


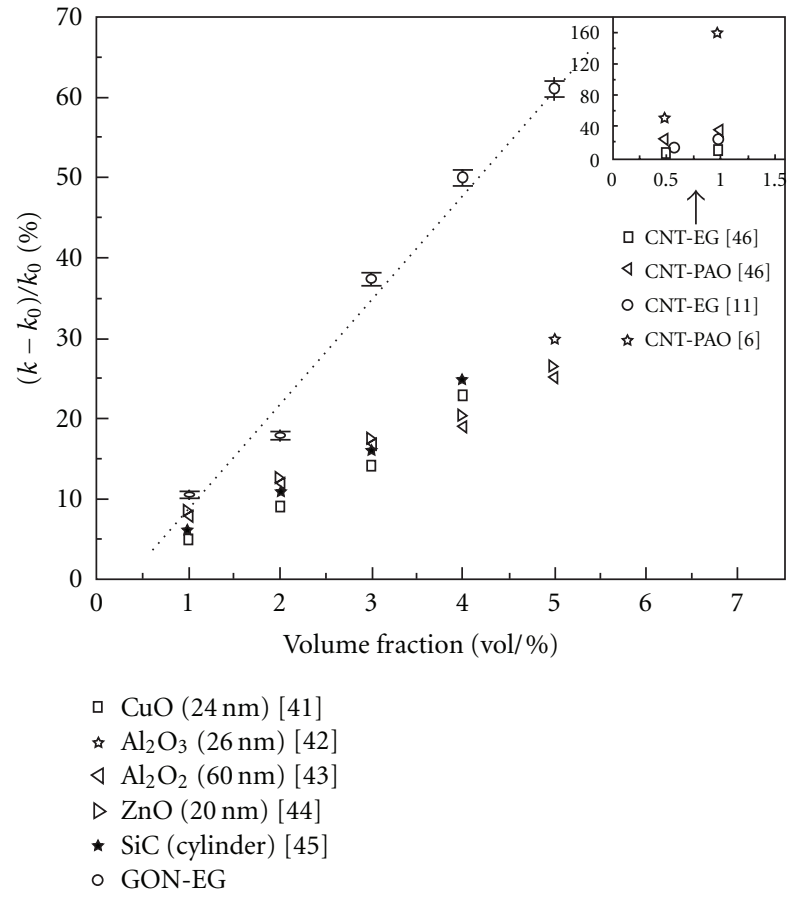

FIgURE 4: Thermal conductivity enhancement ratios of EG-based nanofluids as a function of loading. The inset shows the thermal conductivity enhancement ratios of nanofluids containing CNTs.

\section{Acknowledgments}

The work was supported by New Century Excellent Talents in University (NECT-10-883), the Program for Professor of Special Appointment (Eastern Scholar) at Shanghai Institutions of Higher Learning, and partly by National Natural Science Foundation of China (51106093).

\section{References}

[1] V. Trisaksri and S. Wongwises, "Critical review of heat transfer characteristics of nanofluids," Renewable and Sustainable Energy Reviews, vol. 11, no. 3, pp. 512-523, 2007.

[2] S. Özerinç, S. Kakaç, and A. G. YazIcIoğlu, "Enhanced thermal conductivity of nanofluids: a state-of-the-art review," Microfluidics and Nanofluidics, vol. 8, no. 2, pp. 145-170, 2010.

[3] X. Q. Wang and A. S. Mujumdar, "Heat transfer characteristics of nanofluids: a review," International Journal of Thermal Sciences, vol. 46, no. 1, pp. 1-19, 2007.

[4] X. Q. Wang and A. S. Mujumdar, "A review on nanofluidspart I: theoretical and numerical investigations," Brazilian Journal of Chemical Engineering, vol. 25, no. 4, pp. 613-630, 2008.

[5] Y. Li, J. Zhou, S. Tung, E. Schneider, and S. Xi, "A review on development of nanofluid preparation and characterization," Powder Technology, vol. 196, no. 2, pp. 89-101, 2009.

[6] S. Kakaç and A. Pramuanjaroenkij, "Review of convective heat transfer enhancement with nanofluids," International Journal of Heat and Mass Transfer, vol. 52, no. 13-14, pp. 3187-3196, 2009.
[7] J. A. Eastman, S. U. S. Choi, S. Li, W. Yu, and L. J. Thompson, "Anomalously increased effective thermal conductivities of ethylene glycol-based nanofluids containing copper nanoparticles," Applied Physics Letters, vol. 78, no. 6, pp. 718-720, 2001.

[8] C. H. Lo, T. T. Tsung, and L. C. Chen, "Shape-controlled synthesis of Cu-based nanofluid using submerged arc nanoparticle synthesis system (SANSS)," Journal of Crystal Growth, vol. 277, no. 1-4, pp. 636-642, 2005.

[9] C. H. Lo, T. T. Tsung, L. C. Chen, C. H. Su, and H. M. Lin, "Fabrication of copper oxide nanofluid using submerged arc nanoparticle synthesis system (SANSS)," Journal of Nanoparticle Research, vol. 7, no. 2-3, pp. 313-320, 2005.

[10] H. T. Zhu, Y. S. Lin, and Y. S. Yin, "A novel one-step chemical method for preparation of copper nanofluids," Journal of Colloid and Interface Science, vol. 277, no. 1, pp. 100-103, 2004.

[11] H. Bönnemann, S. S. Botha, B. Bladergroen, and V. M. Linkov, "Monodisperse copper- and silver-nanocolloids suitable for heat-conductive fluids," Applied Organometallic Chemistry, vol. 19, no. 6, pp. 768-773, 2005.

[12] A. K. Singh and V. S. Raykar, "Microwave synthesis of silver nanofluids with polyvinylpyrrolidone (PVP) and their transport properties," Colloid and Polymer Science, vol. 286, no. 14-15, pp. 1667-1673, 2008.

[13] A. Kumar, H. Joshi, R. Pasricha, A. B. Mandale, and M. Sastry, "Phase transfer of silver nanoparticles from aqueous to organic solutions using fatty amine molecules," Journal of Colloid and Interface Science, vol. 264, no. 2, pp. 396-401, 2003.

[14] W. Yu, H. Xie, X. Wang, and X. Wang, "Highly efficient method for preparing homogeneous and stable colloids containing graphene oxide," Nanoscale Research Letters, vol. 6, p. 47, 2011.

[15] H. T. Zhu, C. Y. Zhang, Y. M. Tang, and J. X. Wang, "Novel synthesis and thermal conductivity of $\mathrm{CuO}$ nanofluid," Journal of Physical Chemistry C, vol. 111, no. 4, pp. 16461650, 2007.

[16] Y. Chen and X. Wang, "Novel phase-transfer preparation of monodisperse silver and gold nanoparticles at room temperature," Materials Letters, vol. 62, no. 15, pp. 22152218, 2008.

[17] X. Feng, H. Ma, S. Huang et al., "Aqueous-organic phasetransfer of highly stable gold, silver, and platinum nanoparticles and new route for fabrication of gold nanofilms at the oil/water interface and on solid supports," Journal of Physical Chemistry B, vol. 110, no. 25, pp. 12311-12317, 2006.

[18] W. Yu, H. Xie, L. Chen, and Y. Li, "Enhancement of thermal conductivity of kerosene-based $\mathrm{Fe} 3 \mathrm{O} 4$ nanofluids prepared via phase-transfer method," Colloids and Surfaces A, vol. 355, no. 1-3, pp. 109-113, 2010.

[19] L. Wang and J. Fan, "Nanofluids research: key issues," Nanoscale Research Letters, vol. 5, no. 8, pp. 1241-1252, 2010.

[20] X. Wei and L. Wang, "Synthesis and thermal conductivity of microfluidic copper nanofluids," Particuology, vol. 8, no. 3, pp. 262-271, 2010.

[21] X. Li, D. Zhu, and X. Wang, "Evaluation on dispersion behavior of the aqueous copper nano-suspensions," Journal of Colloid and Interface Science, vol. 310, no. 2, pp. 456-463, 2007.

[22] H. Zhu, C. Zhang, Y. Tang, J. Wang, B. Ren, and Y. Yin, "Preparation and thermal conductivity of suspensions of graphite nanoparticles," Carbon, vol. 45, no. 1, pp. 226-228, 2007. 
[23] D. Li and R. B. Kaner, "Processable stabilizer-free polyaniline nanofiber aqueous colloids," Chemical Communications, vol. 14, no. 26, pp. 3286-3288, 2005.

[24] H. J. Kim, I. C. Bang, and J. Onoe, "Characteristic stability of bare $\mathrm{Au}$-water nanofluids fabricated by pulsed laser ablation in liquids," Optics and Lasers in Engineering, vol. 47, no. 5, pp. 532-538, 2009.

[25] X. J. Wang, X. Li, and S. Yang, "Influence of $\mathrm{pH}$ and SDBS on the stability and thermal conductivity of nanofluids," Energy and Fuels, vol. 23, no. 5, pp. 2684-2689, 2009.

[26] D. Zhu, X. Li, N. Wang, X. Wang, J. Gao, and H. Li, "Dispersion behavior and thermal conductivity characteristics of $\mathrm{Al}_{2} \mathrm{O}_{3}-\mathrm{H}_{2} \mathrm{O}$ nanofluids," Current Applied Physics, vol. 9, no. 1, pp. 131-139, 2009.

[27] L. Chen and H. Xie, "Properties of carbon nanotube nanofluids stabilized by cationic gemini surfactant," Thermochimica Acta, vol. 506, no. 1-2, pp. 62-66, 2010.

[28] J. Huang, X. Wang, Q. Long, X. Wen, Y. Zhou, and L. $\mathrm{Li}$, "Influence of $\mathrm{pH}$ on the stability characteristics of nanofluids," in Proceedings of the Symposium on Photonics and Optoelectronics (SOPO '09), 2009.

[29] M. Farahmandjou, S. A. Sebt, S. S. Parhizgar, P. Aberomand, and M. Akhavan, "Stability investigation of colloidal FePt nanoparticle systems by spectrophotometer analysis," Chinese Physics Letters, vol. 26, no. 2, Article ID 027501, 2009.

[30] Y. Hwang, J. K. Lee, C. H. Lee et al., "Stability and thermal conductivity characteristics of nanofluids," Thermochimica Acta, vol. 455, no. 1-2, pp. 70-74, 2007.

[31] L. Chen, H. Xie, Y. Li, and W. Yu, "Nanofluids containing carbon nanotubes treated by mechanochemical reaction," Thermochimica Acta, vol. 477, no. 1-2, pp. 21-24, 2008.

[32] X. Yang and Z. H. Liu, "A kind of nanofluid consisting of surface-functionalized nanoparticles," Nanoscale Research Letters, vol. 5, no. 8, pp. 1324-1328, 2010.

[33] L. Chen and H. Xie, "Surfactant-free nanofluids containing double- and single-walled carbon nanotubes functionalized by a wet-mechanochemical reaction," Thermochimica Acta, vol. 497, no. 1-2, pp. 67-71, 2010.

[34] K. A. Wepasnick, B. A. Smith, J. L. Bitter, and D. H. Fairbrother, "Chemical and structural characterization of carbon nanotube surfaces," Analytical and Bioanalytical Chemistry, vol. 396, no. 3, pp. 1003-1014, 2010.

[35] Q. Yu, Y. J. Kim, and H. Ma, "Nanofluids with plasma treated diamond nanoparticles," Applied Physics Letters, vol. 92, no. 10, Article ID 103111, 2008.

[36] I. M. Joni, A. Purwanto, F. Iskandar, and K. Okuyama, "Dispersion stability enhancement of titania nanoparticles in organic solvent using a bead mill process," Industrial and Engineering Chemistry Research, vol. 48, no. 15, pp. 69166922, 2009.

[37] E. Tang, G. Cheng, X. Ma, X. Pang, and Q. Zhao, "Surface modification of zinc oxide nanoparticle by PMAA and its dispersion in aqueous system," Applied Surface Science, vol. 252, no. 14, pp. 5227-5232, 2006.

[38] T. Missana and A. Adell, "On the applicability of DLVO theory to the prediction of clay colloids stability," Journal of Colloid and Interface Science, vol. 230, no. 1, pp. 150-156, 2000.

[39] I. Popa, G. Gillies, G. Papastavrou, and M. Borkovec, "Attractive and repulsive electrostatic forces between positively charged latex particles in the presence of anionic linear polyelectrolytes," Journal of Physical Chemistry B, vol. 114, no. 9 , pp. 3170-3177, 2010.
[40] H. Kamiya, Y. Fukuda, Y. Suzuki, M. Tsukada, T. Kakui, and M. Naito, "Effect of polymer dispersant structure on electrosteric interaction and dense alumina suspension behavior," Journal of the American Ceramic Society, vol. 82, no. 12, pp. 3407-3412, 1999.

[41] K. V. Wong and O. de Leon, "Applications of nanofluids: current and future," Advances in Mechanical Engineering, vol. 2010, Article ID 519659, 11 pages, 2010.

[42] G. Donzelli, R. Cerbino, and A. Vailati, "Bistable heat transfer in a nanofluid," Physical Review Letters, vol. 102, no. 10, Article ID 104503, 2009.

[43] M. Arruebo, R. Fernández-Pacheco, M. R. Ibarra, and J. Santamaría, "Magnetic nanoparticles for drug delivery," Nano Today, vol. 2, no. 3, pp. 22-32, 2007.

[44] W. Yu, D. M. France, D. Singh, E. V. Timofeeva, D. S. Smith, and J. L. Routbort, "Mechanisms and models of effective thermal conductivities of nanofluids," Journal of Nanoscience and Nanotechnology, vol. 10, no. 8, pp. 4824-4849, 2010.

[45] K. Q. Ma and J. Liu, "Nano liquid-metal fluid as ultimate coolant," Physics Letters Section A, vol. 361, no. 3, pp. 252256, 2007.

[46] G. Paul, M. Chopkar, I. Manna, and P. K. Das, “Techniques for measuring the thermal conductivity of nanofluids: a review," Renewable and Sustainable Energy Reviews, vol. 14, p. 1913, 2010.

[47] H. Xie, W. Yu, and W. Chen, "MgO nanofluids: higher thermal conductivity and lower viscosity among ethylene glycol-based nanofluids containing oxide nanoparticles," Journal of Experimental Nanoscience, vol. 5, no. 5, pp. 463$472,2010$.

[48] S. P. Jang and S. U. S. Choi, "Cooling performance of a microchannel heat sink with nanofluids," Applied Thermal Engineering, vol. 26, no. 17-18, pp. 2457-2463, 2006.

[49] C. T. Nguyen, G. Roy, N. Galanis, and S. Suiro, "Heat transfer enhancement by using $\mathrm{Al}_{2} \mathrm{O}_{3}$-water nanofluid in a liquid cooling system for microprocessors," in Proceedings of the 4th WSEAS International Conference on Heat Transfer, Thermal Engineering and Environment, pp. 103-108, Elounda, Greece, August 2006.

[50] H. Shokouhmand, M. Ghazvini, and J. Shabanian, "Performance analysis of using nanofluids in microchannel heat sink in different flow regimes and its simulation using artificial neural network," in Proceedings of the World Congress on Engineering (WCE '08), vol. 3, London, UK, July 2008.

[51] C. Y. Tsaia, H. T. Chiena, P. P. Dingb, B. Chanc, T. Y. Luhd, and P. H. Chena, "Effect of structural character of gold nanoparticles in nanofluid on heat pipe thermal performance," Materials Letters, vol. 58, p. 1461, 2004.

[52] Y. T. Chen, W. C. Wei, S. W. Kang, and C. S. Yu, "Effect of nanofluid on flat heat pipe thermal performance," in Proceedings of the 24th IEEE Semiconductor Thermal Measurement and Management Symposium (SEMI-THERM '08), March 2006.

[53] H. B. Ma, C. Wilson, B. Borgmeyer et al., "Effect of nanofluid on the heat transport capability in an oscillating heat pipe," Applied Physics Letters, vol. 88, no. 14, Article ID 143116, 2006.

[54] S. W. Kang, W. C. Wei, S. H. Tsai, and C. C. Huang, "Experimental investigation of nanofluids on sintered heat pipe thermal performance," Applied Thermal Engineering, vol. 29, no. 5-6, pp. 973-979, 2009.

[55] P. Naphon, P. Assadamongkol, and T. Borirak, "Experimental investigation of titanium nanofluids on the heat pipe thermal 
efficiency," International Communications in Heat and Mass Transfer, vol. 35, no. 10, pp. 1316-1319, 2008.

[56] H. Xie and L. Chen, "Adjustable thermal conductivity in carbon nanotube nanofluids," Physics Letters Section A, vol. 373, no. 21, pp. 1861-1864, 2009.

[57] H. Xie, W. Yu, and Y. Li, "Thermal performance enhancement in nanofluids containing diamond nanoparticles," Journal of Physics D, vol. 42, no. 9, Article ID 095413, 2009.

[58] W. Yu, H. Xie, L. Chen, and Y. Li, "Investigation of thermal conductivity and viscosity of ethylene glycol based $\mathrm{ZnO}$ nanofluid," Thermochimica Acta, vol. 491, no. 1-2, pp. 92-96, 2009.

[59] W. Yu, D. M. France, S. U. S. Choi, and J. L. Routbort, "Review and assessment of nanofluid technology for transportation and other applications," Tech. Rep. 78, ANL/ESD/07-9, Argonne National Laboratory, 2007.

[60] M. Kole and T. K. Dey, "Thermal conductivity and viscosity of $\mathrm{Al} 2 \mathrm{O} 3$ nanofluid based on car engine coolant," Journal of Physics D, vol. 43, no. 31, Article ID 315501, 2010.

[61] S. C. Tzeng, C. W. Lin, and K. D. Huang, "Heat transfer enhancement of nanofluids in rotary blade coupling of fourwheel-drive vehicles," Acta Mechanica, vol. 179, no. 1-2, pp. 11-23, 2005.

[62] D. Singh, J. Toutbort, G. Chen et al., "Heavy vehicle systems optimization merit review and peer evaluation," Annual Report, Argonne National Laboratory, 2006.

[63] http://www.labnews.co.uk/feature_archive.php/5449/5/keeping-it-cool.

[64] J. Routbort et al., Argonne National Lab, Michellin North America,St. Gobain Corp., 2009, http://www1.eere.energy.gov/industry/nanomanufacturing/pdfs/nanofluidsindusttrialcooling.pdf.

[65] http://96.30.12.13/execsumm/VU0319-Nanofluid\%20for $\% 20$ Cooling $\% 20$ Enhancement $\% 20$ of $\% 20$ Electrical $\% 20$ Power\%20Equipment.pdf.

[66] I. C. Nelson, D. Banerjee, and R. Ponnappan, "Flow loop experiments using polyalphaolefin nanofluids," Journal of Thermophysics and Heat Transfer, vol. 23, no. 4, pp. 752-761, 2009.

[67] D. P. Kulkarni, D. K. Das, and R. S. Vajjha, "Application of nanofluids in heating buildings and reducing pollution," Applied Energy, vol. 86, no. 12, pp. 2566-2573, 2009.

[68] J. Boungiorno, L. W. Hu, S. J. Kim, R. Hannink, B. Truong, and E. Forrest, "Nanofluids for enhanced economics and safety of nuclear reactors: an evaluation of the potential features issues, and research gaps," Nuclear Technology, vol. 162, no. 1, pp. 80-91, 2008.

[69] S. M. You, J. H. Kim, and K. H. Kim, "Effect of nanoparticles on critical heat flux of water in pool boiling heat transfer," Applied Physics Letters, vol. 83, no. 16, pp. 3374-3376, 2003.

[70] P. Vassallo, R. Kumar, and S. D'Amico, "Pool boiling heat transfer experiments in silica-water nano-fluids," International Journal of Heat and Mass Transfer, vol. 47, no. 2, pp. 407-411, 2004.

[71] J. K. Kim, J. Y. Jung, and Y. T. Kang, "The effect of nanoparticles on the bubble absorption performance in a binary nanofluid," International Journal of Refrigeration, vol. 29, no. 1, pp. 22-29, 2006.

[72] J. K. Kim, J. Y. Jung, and Y. T. Kang, “Absorption performance enhancement by nano-particles and chemical surfactants in binary nanofluids," International Journal of Refrigeration, vol. 30 , no. 1 , pp. $50-57,2007$.
[73] J. Kim, Y. T. Kang, and C. K. Choi, "Soret and Dufour effects on convective instabilities in binary nanofluids for absorption application," International Journal of Refrigeration, vol. 30, no. 2, pp. 323-328, 2007.

[74] X. Ma, F. Su, J. Chen, and Y. Zhang, "Heat and mass transfer enhancement of the bubble absorption for a binary nanofluid," Journal of Mechanical Science and Technology, vol. 21, p. 1813, 2007.

[75] X. Ma, F. Su, J. Chen, T. Bai, and Z. Han, "Enhancement of bubble absorption process using a CNTs-ammonia binary nanofluid," International Communications in Heat and Mass Transfer, vol. 36, no. 7, pp. 657-660, 2009.

[76] S. Komati and A. K. Suresh, "CO2 absorption into amine solutions: a novel strategy for intensification based on the addition of ferrofluids," Journal of Chemical Technology and Biotechnology, vol. 83, no. 8, pp. 1094-1100, 2008.

[77] L. Yang, K. Du, B. Cheng, and Y. Jiang, "The influence of $\mathrm{Al} 2 \mathrm{O} 3$ nanofluid on the falling film absorption with ammonia-water," in Proceedings of the Asia-Pacific Power and Energy Engineering Conference (APPEEC '10), 2010.

[78] M. F. Demirbas, “Thermal energy storage and phase change materials: an overview," Energy Sources Part B, vol. 1, no. 1, pp. 85-95, 2006.

[79] S. Wu, D. Zhu, X. Zhang, and J. Huang, "Preparation and melting/freezing characteristics of $\mathrm{Cu}$ /paraffin nanofluid as phase-change material (PCM)," Energy and Fuels, vol. 24, no. 3, pp. 1894-1898, 2010.

[80] Y. D. Liu, Y. G. Zhou, M. W. Tong, and X. S. Zhou, "Experimental study of thermal conductivity and phase change performance of nanofluids PCMs," Microfluidics and Nanofluidics, vol. 7, no. 4, pp. 579-584, 2009.

[81] T. P. Otanicar, P. E. Phelan, R. S. Prasher, G. Rosengarten, and R. A. Taylor, "Nanofluid-based direct absorption solar collector," Journal of Renewable and Sustainable Energy, vol. 2, no. 3, Article ID 033102, 13 pages, 2010.

[82] H. Tyagi, P. Phelan, and R. Prasher, "Predicted efficiency of a low-temperature Nanofluid-based direct absorption solar collector," Journal of Solar Energy Engineering, vol. 131, no. 4, pp. 0410041-0410047, 2009.

[83] T. P. Otanicar and J. S. Golden, "Comparative environmental and economic analysis of conventional and nanofluid solar hot water technologies," Environmental Science and Technology, vol. 43, no. 15, pp. 6082-6087, 2009.

[84] E. Sani, S. Barison, C. Pagura et al., "Carbon nanohornsbased nanofluids as direct sunlight absorbers," Optics Express, vol. 18, p. 4613, 2010.

[85] J. Zhou, Z. Wu, Z. Zhang, W. Liu, and Q. Xue, "Tribological behavior and lubricating mechanism of $\mathrm{Cu}$ nanoparticles in oil," Tribology Letters, vol. 8, no. 4, pp. 213-218, 2000.

[86] B. Shen, A. J. Shih, and S. C. Tung, "Application of nanofluids in minimum quantity lubrication grinding," Tribology Transactions, vol. 51, no. 6, pp. 730-737, 2008.

[87] H. L. Yu, Y. Xu, P. J. Shi, B. S. Xu, X. L. Wang, and Q. Liu, "Tribological properties and lubricating mechanisms of $\mathrm{Cu}$ nanoparticles in lubricant," Transactions of Nonferrous Metals Society of China, vol. 18, no. 3, pp. 636-641, 2008.

[88] B. Yu, Z. Liu, F. Zhou, W. Liu, and Y. Liang, "A novel lubricant additive based on carbon nanotubes for ionic liquids," Materials Letters, vol. 62, no. 17-18, pp. 2967-2969, 2008.

[89] B. Wang, X. Wang, W. Lou, and J. Hao, "Rheological and tribological properties of ionic liquid-based nanofluids 
containing functionalized multi-walled carbon nanotubes," Journal of Physical Chemistry C, vol. 114, no. 19, pp. 87498754, 2010.

[90] L. J. Wang, C. W. Guo, and R. Yamane, "Experimental research on tribological properties of $\mathrm{Mn}_{0.78} \mathrm{Zn}_{0.22} \quad \mathrm{FE}_{2} \mathrm{O}_{4}$ magnetic fluids," Journal of Tribology, vol. 130, no. 3, Article ID 031801, 2008.

[91] S. Chen and D. H. Mao, "Study on dispersion stability and self-repair principle of ultrafine-tungsten disulfide particulates ," Advanced Tribology, vol. 995, 2010.

[92] D. X. Peng, C. H. Chen, Y. Kang, Y. P. Chang, and S. Y. Chang, "Size effects of $\mathrm{SiO}_{2}$ nanoparticles as oil additives on tribology of lubricant," Industrial Lubrication and Tribology, vol. 62, no. 2, pp. 111-120, 2010.

[93] L. Vékás, D. Bica, and M. V. Avdeev, "Magnetic nanoparticles and concentrated magnetic nanofluids: synthesis, properties and some applications," China Particuology, vol. 5, no. 1-2, pp. 43-49, 2007.

[94] R. E. Rosensweig, "Magnetic fluids," Annual Review of Fluid Mechanics, vol. 19, pp. 437-463, 1987.

[95] Y. S. Kim, K. Nakatsuka, T. Fujita, and T. Atarashi, "Application of hydrophilic magnetic fluid to oil seal," Journal of Magnetism and Magnetic Materials, vol. 201, no. 1-3, pp. 361-363, 1999.

[96] Y. Mitamura, S. Arioka, D. Sakota, K. Sekine, and M. Azegami, "Application of a magnetic fluid seal to rotary blood pumps," Journal of Physics Condensed Matter, vol. 20, no. 20, Article ID 204145, 2008.

[97] Y. S. Kim and Y. H. Kim, "Application of ferro-cobalt magnetic fluid for oil sealing," Journal of Magnetism and Magnetic Materials, vol. 267, no. 1, pp. 105-110, 2003.

[98] L. Zhang, Y. Jiang, Y. Ding, M. Povey, and D. York, "Investigation into the antibacterial behaviour of suspensions of $\mathrm{ZnO}$ nanoparticles (ZnO nanofluids)," Journal of Nanoparticle Research, vol. 9, no. 3, pp. 479-489, 2007.

[99] R. Jalal, E. K. Goharshadi, M. Abareshi, M. Moosavi, A. Yousefi, and P. Nancarrow, "ZnO nanofluids: green synthesis, characterization, and antibacterial activity," Materials Chemistry and Physics, vol. 121, no. 1-2, pp. 198-201, 2010.

[100] N. Jones, B. Ray, K. T. Ranjit, and A. C. Manna, "Antibacterial activity of $\mathrm{ZnO}$ nanoparticle suspensions on a broad spectrum of microorganisms," FEMS Microbiology Letters, vol. 279, no. 1, pp. 71-76, 2008.

[101] Y. Liu, L. He, A. Mustapha, H. Li, Z. Q. Hu, and M. Lin, "Antibacterial activities of zinc oxide nanoparticles against Escherichia coli O157:H7," Journal of Applied Microbiology, vol. 107, no. 4, pp. 1193-1201, 2009.

[102] O. Mahapatra, M. Bhagat, C. Gopalakrishnan, and K. D. Arunachalam, "Ultrafine dispersed $\mathrm{CuO}$ nanoparticles and their antibacterial activity," Journal of Experimental Nanoscience, vol. 3, no. 3, pp. 185-193, 2008.

[103] P. Gajjar, B. Pettee, D. W. Britt, W. Huang, W. P. Johnson, and A. J. Anderson, "Antimicrobial activities of commercial nanoparticles against an environmental soil microbe, Pseudomonas putida KT2440," Journal of Biological Engineering, vol. 3, p. 9, 2009.

[104] H. J. Lee, S. Y. Yeo, and S. H. Jeong, "Antibacterial effect of nanosized silver colloidal solution on textile fabrics," Polymer Journal, vol. 8, p. 2199, 2003.

[105] A. Panáček, L. Kvítek, R. Prucek et al., "Silver colloid nanoparticles: synthesis, characterization, and their antibacterial activity," Journal of Physical Chemistry B, vol. 110, no. 33, pp. 16248-16253, 2006.
[106] L. Brunet, D. Y. Lyon, E. M. Hotze, P. J. J. Alvarez, and M. R. Wiesner, "Comparative photoactivity and antibacterial properties of C60 fullerenes and titanium dioxide nanoparticles," Environmental Science and Technology, vol. 43, no. 12, pp. 4355-4360, 2009.

[107] D. Y. Lyon and P. J. J. Alvarez, "Fullerene water suspension $\left(\mathrm{nC}_{60}\right)$ exerts antibacterial effects via ROS-independent protein oxidation," Environmental Science and Technology, vol. 42, no. 21, pp. 8127-8132, 2008.

[108] A. Vonarbourg, C. Passirani, P. Saulnier, and J. P. Benoit, "Parameters influencing the stealthiness of colloidal drug delivery systems," Biomaterials, vol. 27 , no. 24 , pp. $4356-$ 4373, 2006.

[109] R. Singh and J. W. Lillard, "Nanoparticle-based targeted drug delivery," Experimental and Molecular Pathology, vol. 86, no. 3, pp. 215-223, 2009.

[110] P. Ghosh, G. Han, M. De, C. K. Kim, and V. M. Rotello, "Gold nanoparticles in delivery applications," Advanced Drug Delivery Reviews, vol. 17, p. 1307, 2008.

[111] M. Nakano, H. Matsuura, D. Ju et al., "Drug delivery system using nano-magnetic fluid," in Proceedings of the 3rd International Conference on Innovative Computing, Information and Control (ICICIC '08), Dalian, China, June 2008.

[112] A. Bianco, K. Kostarelos, and M. Prato, "Applications of carbon nanotubes in drug delivery," Current Opinion in Chemical Biology, vol. 9, no. 6, pp. 674-679, 2005.

[113] C. Tripisciano, K. Kraemer, A. Taylor, and E. BorowiakPalen, "Single-wall carbon nanotubes based anticancer drug delivery system," Chemical Physics Letters, vol. 478, no. 4-6, pp. 200-205, 2009.

[114] G. Pastorin, W. Wu, S. Wieckowski et al., "Double functionalisation of carbon nanotubes for multimodal drug delivery," Chemical Communications, no. 11, pp. 1182-1184, 2006.

[115] Z. Liu, X. Sun, N. Nakayama-Ratchford, and H. Dai, "Supramolecular chemistry on water-soluble carbon nanotubes for drug loading and delivery," ACS nano, vol. 1, no. 1, pp. 50-56, 2007.

[116] X. Sun, Z. Liu, J. T. Robinson et al., "Nano-graphene oxide for cellular imaging and drug delivery," Nano Research, vol. 1, p. 203, 2008.

[117] L. Zhang, J. Xia, Q. Zhao, L. Liu, and Z. Zhang, "Functional graphene oxide as a nanocarrier for controlled loading and targeted delivery of mixed anticancer drugs," Small, vol. 6, no. 4, pp. 537-544, 2010

[118] Z. Liu, J. T. Robinson, X. Sun, and H. Dai, "PEGylated nanographene oxide for delivery of water-insoluble cancer drugs," Journal of the American Chemical Society, vol. 130, no. 33, pp. 10876-10877, 2008.

[119] X. Yang, X. Zhang, Y. Ma, Y. Huang, Y. Wang, and Y. Chen, "Superparamagnetic graphene oxide- $\mathrm{Fe}_{3} \mathrm{O}_{4}$ nanoparticles hybrid for controlled targeted drug carriers," Journal of Materials Chemistry, vol. 19, no. 18, pp. 2710-2714, 2009.

[120] X. Fan, H. Chen, Y. Ding, P. K. Plucinski, and A. A. Lapkin, "Potential of 'nanofluids' to further intensify microreactors," Green Chemistry, vol. 10, no. 6, pp. 670-677, 2008.

[121] M. J. Kao, C. H. Lo, T. T. Tsung, Y. Y. Wu, C. S. Jwo, and H. M. Lin, "Copper-oxide brake nanofluid manufactured using arcsubmerged nanoparticle synthesis system," Journal of Alloys and Compounds, vol. 434-435, pp. 672-674, 2007.

[122] M. J. Kao, H. Chang, Y. Y. Wu, T. T. Tsung, and H. M. Lin, "Producing Aluminum-oxide brake nanofluids derived using plasma charging system," Journal of the Chinese Society of Mechanical Engineers, vol. 28, p. 123, 2007. 
[123] T. Sharma, A. L. M. Reddy, T. S. Chandra, and S. Ramaprabhu, "Development of carbon nanotubes and nanofluids based microbial fuel cell," International Journal of Hydrogen Energy, vol. 33, no. 22, pp. 6749-6754, 2008.

[124] J. Philip, T. Jaykumar, P. Kalyanasundaram, and B. Raj, "A tunable optical filter," Measurement Science and Technology, vol. 14, no. 8, pp. 1289-1294, 2003.

[125] A. Mishra, P. Tripathy, S. Ram, and H. J. Fecht, "Optical properties in nanofluids of gold nanoparticles in poly(vinylpyrrolidone)," Journal of Nanoscience and Nanotechnology, vol. 9, no. 7, pp. 4342-4347, 2009.

[126] W. Yu, H. Xie, and D. Bao, "Enhanced thermal conductivities of nanofluids containing graphene oxide nanosheets," Nanotechnology, vol. 21, no. 5, Article ID 055705, 2010.

[127] W. Yu, H. Xie, and W. Chen, "Experimental investigation on thermal conductivity of nanofluids containing graphene oxide nanosheets," Journal of Applied Physics, vol. 107, no. 9, Article ID 094317, 2010.

[128] Z. H. Han, F. Y. Cao, and B. Yang, "Synthesis and thermal characterization of phase-changeable indium/polyalphaolefin nanofluids," Applied Physics Letters, vol. 92, no. 24, Article ID 243104, 2008. 

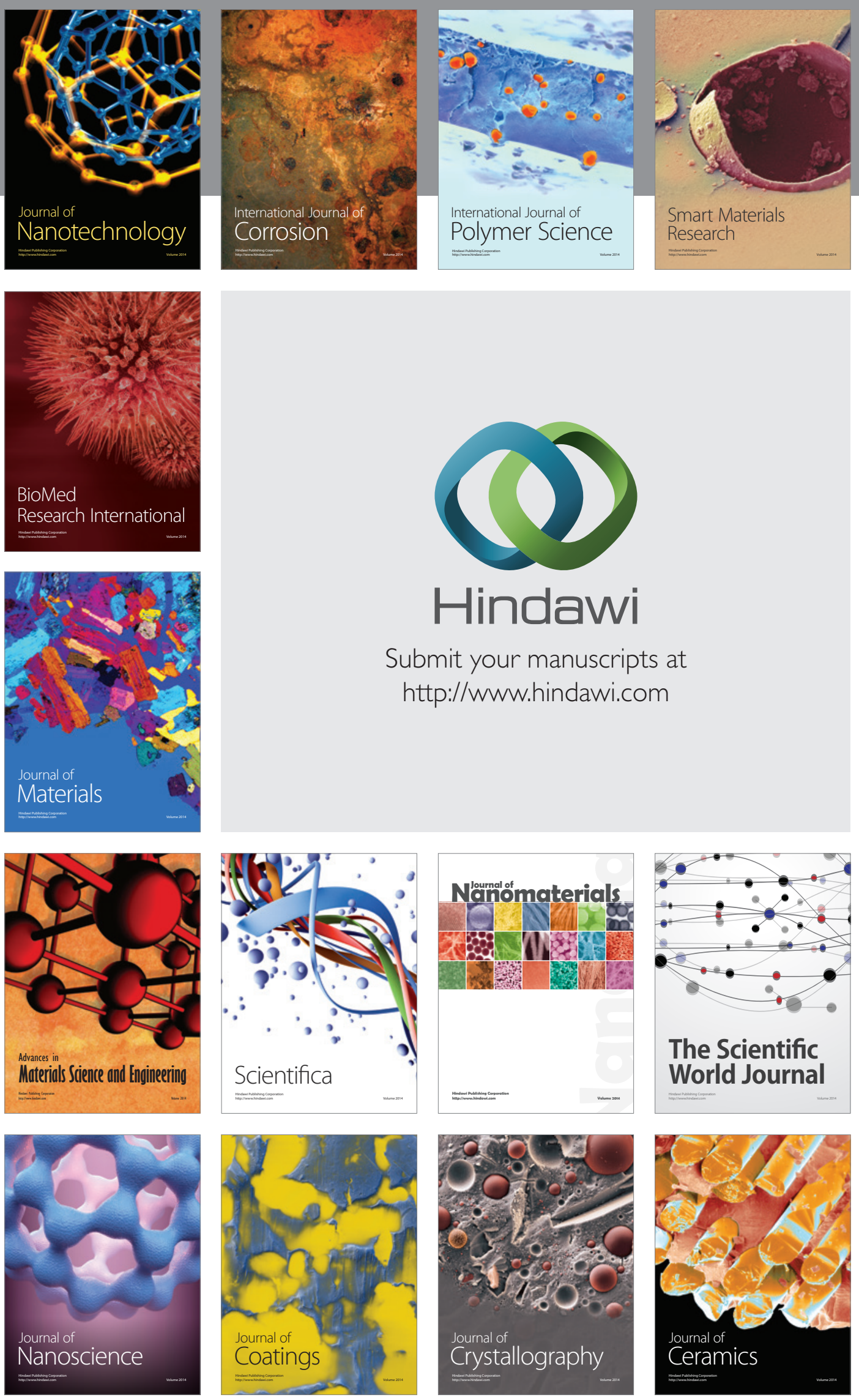

The Scientific World Journal

Submit your manuscripts at

http://www.hindawi.com

\section{World Journal}

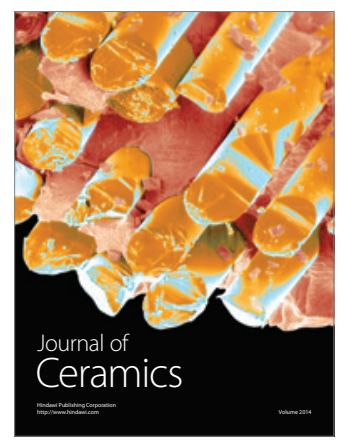

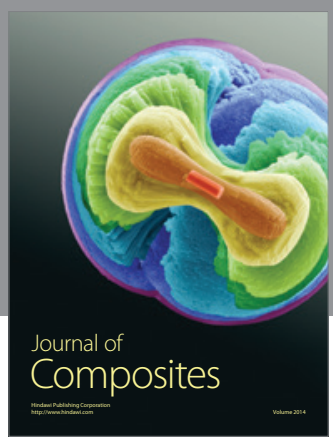
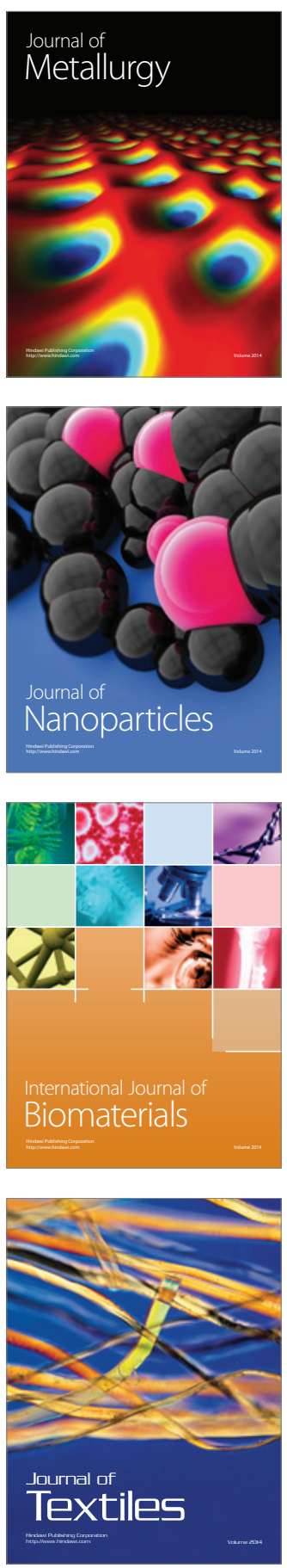